\title{
Using Simplified Models to Assist Fault Detection and Diagnosis in Large Hydrogenerators
}

\author{
Geraldo Carvalho Brito Junior, ${ }^{1,2}$ Roberto Dalledone Machado, ${ }^{2}$ and Anselmo Chaves Neto ${ }^{2}$ \\ ${ }^{1}$ Center for Engineering and Exact Sciences, Western Paraná State University (UNIOESTE), Foz do Iguaçu, PR, Brazil \\ ${ }^{2}$ Numerical Methods for Engineering Graduate Program, Federal University of Paraná (UFPR), Curitiba, PR, Brazil \\ Correspondence should be addressed to Geraldo Carvalho Brito Junior; gcbritojr@gmail.com
}

Received 8 December 2016; Revised 25 February 2017; Accepted 6 March 2017; Published 27 April 2017

Academic Editor: Dong Wang

Copyright (c) 2017 Geraldo Carvalho Brito Junior et al. This is an open access article distributed under the Creative Commons Attribution License, which permits unrestricted use, distribution, and reproduction in any medium, provided the original work is properly cited.

\begin{abstract}
Based on experimental evidence collected in a set of twenty $700 \mathrm{MW}$ hydrogenerators, this article shows that the operating conditions of large hydrogenerators journal bearings may have unpredictable and significant changes, without apparent reasons. These changes prevent the accurate determination of bearing dynamic coefficients and make the prediction of these machines dynamic behavior unfeasible, even using refined models. This makes it difficult to differentiate the normal changes in hydrogenerators dynamics from the changes created by a fault event. To overcome such difficulty, this article proposes a backto-basics step, the using of simplified mathematical models to assist hydrogenerators vibration monitoring and exemplifies this proposal by modeling a $700 \mathrm{MW}$ hydrogenerator. A first model estimates the influence of changes in bearing operating conditions in the bearing stiffnesses, considering only the hydrodynamic effects of an isoviscous oil film with linear thickness distribution. A second model simulates hydrogenerators dynamics using only 10 degrees of freedom, giving the monitored vibrations as outputs, under normal operating conditions or in the presence of a fault. This article shows that simplified models may give satisfactory results when bearing operating conditions are properly determined, results comparable to those obtained by more refined models or by measurements in the modeled hydrogenerator.
\end{abstract}

\section{Introduction}

Due to the strategic importance of large hydrogenerators (LHG) and due to the potential risk of catastrophic failures [1], the application of vibration-based condition monitoring to these machines is a real necessity. LHG are vertical rotating machines with a complex vibratory behavior [2]. As will be exemplified in the following sections, the operating and the boundary conditions of LHG journal bearings may experience unpredictable and significant changes, without apparent reasons. Due to this, the bearing dynamic coefficients cannot be determined with an adequate accuracy even by the most sophisticated mathematical models. Also, as a consequence, the dynamic behavior of LHG may have similar erratic and substantial changes, preventing satisfactory theoretical predictions even when using refined models. This complicates fault detection and fault diagnosis using pattern recognition approach $[3,4]$, as it is difficult to differentiate the normal and typical changes in the dynamic behavior of these machines from those changes originated by the advent of a fault. Moreover, several faults that frequently happen in LHG begin in the journal bearings or have strong influences in their dynamic coefficients $[2,5]$. Therefore, the understanding of journal bearing dynamics has a central importance in fault detection and fault diagnosis in LHG.

Considering this situation, this article proposes a backto-basics step, the using of simplified mathematical models to assist fault detection and fault diagnosis in LHG. It illustrates this proposal by modeling a $700 \mathrm{MW}$ hydrogenerator, with different purposes. Since it is easier to estimate and to monitor bearing stiffness than bearing damping and considering also that both parameters have similar sensitivity to faults [6], this article focuses on bearing stiffness. A first model is used to estimate the influence of changes in bearing operating conditions in the bearing stiffness, considering only the hydrodynamic effects of an isoviscous oil film with a linear thickness 
distribution. A second model simulates the dynamic behavior of LHG under normal operating conditions or in the presence of the more frequent faults, taking into account gyroscopic effects and bearing anisotropy, but using a simplified Rigid Body Model with only 10 degrees of freedom (DOF). Based on the results of these applications, this article shows that these simplified mathematical models give suitable results when bearing conditions are properly determined, results comparable to the those obtained using more advanced mathematical models or to real measurements in the modeled hydrogenerators.

Besides this introductory section, this article is structured as follows. Section 2 presents some experimental results and a brief review of mathematical modeling applied to LHG, which justify the using of simplified models to assist the application of vibration-based condition monitoring techniques to these machines. Section 3 describes the two formerly mentioned mathematical models, including their validation. Section 4 shows applications of these models under the several possible operating conditions of the journal bearings and presents a discussion of the obtained results. Section 5 presents the concluding remarks of this article.

\section{Remarks on LHG Models}

2.1. Some Remarks on Experimental Aspects. The experimental aspects and the numerical simulations described in this article are related to the $700 \mathrm{MW}$ hydrogenerators of Itaipu, a $14000 \mathrm{MW}$ hydroelectric power plant operated by a binational company belonging to both Brazil and Paraguay governments. Figure 1 shows a typical hydrogenerator, which is composed of the generator rotor (1), the turbine runner (2), the generator upper (3) and lower (4) shafts, and the turbine shaft (5). The moment of inertia in rotation $\left(G D^{2}\right)$ is $332.10^{6} \mathrm{kgm}^{2}$ and the nominal rotating speeds are $90.9 \mathrm{rpm}$ for the ten $50 \mathrm{~Hz}$ units and $92.3 \mathrm{rpm}$ for the remaining ten $60 \mathrm{~Hz}$ units. This figure also shows the upper journal bearing (6), the combined thrust and lower journal bearing (7), and the turbine journal bearing (8). Finally, Figure 1 shows the upper bearing bracket (9), the combined bearing bracket (10), and the turbine head cover (11).

Figure 2 shows the typical arrangement of the vibration transducers in the journal bearings. Each bearing has two inductive proximity transducers with a sensitivity of $4 \mathrm{~V} / \mathrm{mm}$, used to measure the shaft relative vibrations. These transducers are installed $90^{\circ}$ apart from each other, fixed in the structure that holds the bearing pads. Two low-frequency piezoelectric accelerometers, of industrial type and high sensitivity $(1000 \mathrm{mV} / \mathrm{g})$, measure the bearing absolute vibrations. These accelerometers are installed in the same structure that holds the proximity transducers, aligned with these transducers. Charge amplifiers integrate the acceleration signals; therefore, the bearing vibrations are expressed in velocity on this article. The proximity transducers and accelerometers are of accuracy class 5\%, which was confirmed for each transducer, by laboratory calibration tests, before installation. These transducers and their assembly in the journal bearings fulfill the requirements and the recommendations prescribed in the applicable international standards $[7,8]$.

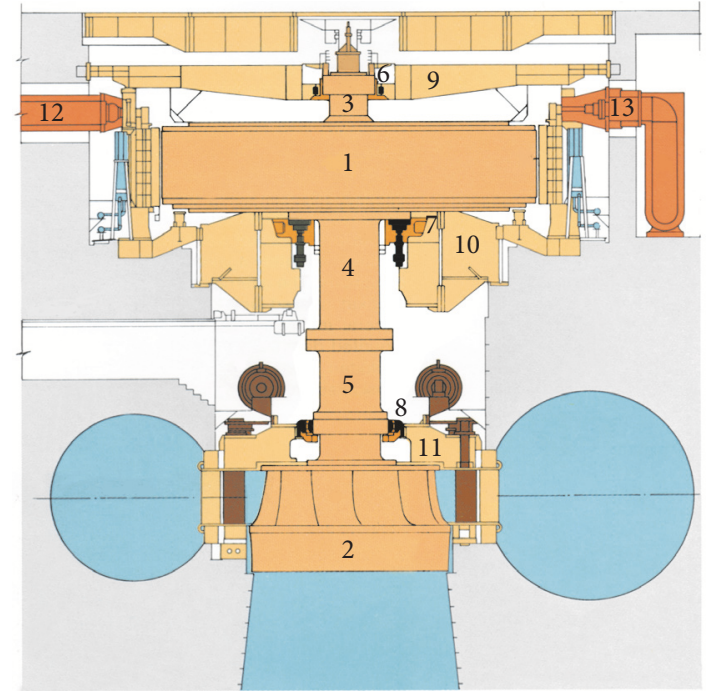

FIGURE 1: View of a typical $700 \mathrm{MW}$ hydrogenerator of Itaipu Power Plant.

This section describes following some phenomena experimentally observed in the LHG, which have significant influence in the mathematical modeling, and in the vibrationbased condition monitoring of these machines. Reference [9] gives a more complete and detailed description of this type of phenomena. The first phenomenon concerns the radial static loads in the journal bearings of LHG. These bearings are subject to radial static loads like the magnetic load originated by misalignment between generator stator and rotor, as well as like the hydraulic load created by the uneven distribution of the water flow in the turbine wicket gates. Table 1 shows the radial static loads measured in the upper and lower journal bearings of an LHG during bearings special commissioning tests [10]. These journal bearings, equipped with 16 tilting pads regularly spaced, are subject to radial static loads with random and expressive changes in amplitude (from 20 to $360 \mathrm{kN}$ ) and direction (over $180^{\circ}$ or 8 pads).

Each diagram of Figure 3 shows the average values of two shaft relative vibrations measured $90^{\circ}$ apart in the plane of the three journal bearings of an LHG, plotted against each other. The marks on the diagrams are related to the shaft center position or the shaft eccentricity in the journal bearing. The diameters of the red circles in dashed lines are equal to the nominal values of bearings diametral clearances in operation. Five measurements were taken over a month $(4 / 3,4 / 7,4 / 14$, $4 / 22$, and 4/29) and the remaining five measurements were taken eight months later, also during a period of a month $(1 / 6,1 / 14,1 / 21,1 / 22$, and $1 / 28)$. The generator load varied from 475 to $700 \mathrm{MW}$ during these measurements. Figure 3 shows that shaft eccentricity may have significant and unpredictable variations. However, this operating parameter may be estimated for vibration monitoring applications using the shaft relative vibrations, as described previously.

Figure 4 shows four different distributions of pad clearances in the upper journal bearing of an LHG, which are used in the simulations described in the following sections. 


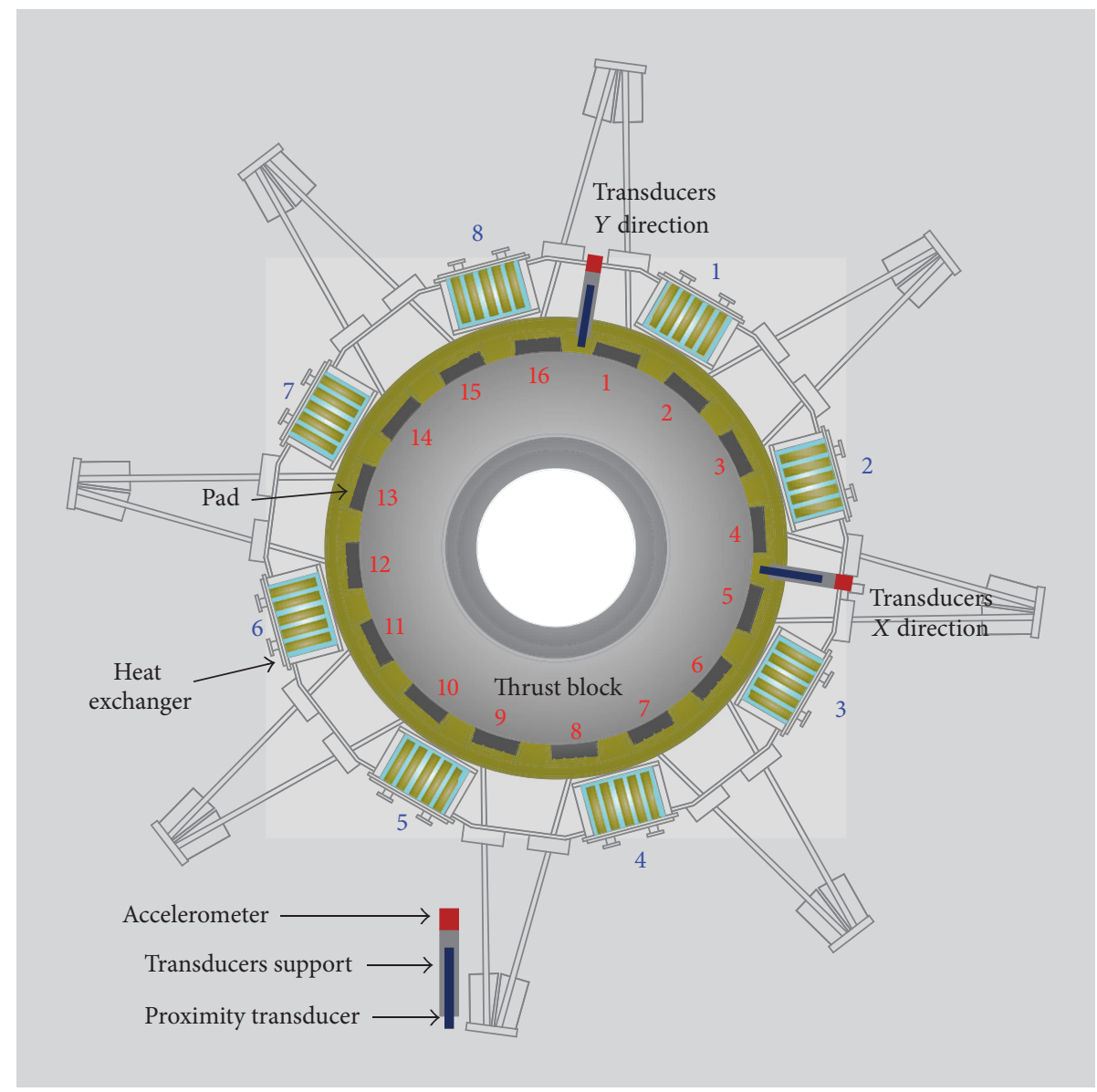

FIGURE 2: Transducers arrangement in the lower journal bearing.

TABLE 1: Radial static loads measured in the journal bearings of an LHG.

\begin{tabular}{|c|c|c|c|c|c|}
\hline \multicolumn{2}{|c|}{ Operating condition } & \multicolumn{2}{|c|}{ Upper bearing } & \multicolumn{2}{|c|}{ Lower bearing } \\
\hline Speed $[\mathrm{r} / \mathrm{min}]$ & Power [MW] & Load $[\mathrm{kN}]$ & Directed to Pad & Load $[\mathrm{kN}]$ & Directed to Pad \\
\hline 78.5 & 0 & 31 & 13 & 21 & 7 \\
\hline 92.3 & 0 & 61 & 8 & 91 & 14 \\
\hline 92.3 & 600 & 248 & 15 & 295 & 7 \\
\hline 92.3 & 700 & 274 & 10 & 294 & 15 \\
\hline 92.3 & 700 & 316 & 16 & 355 & 9 \\
\hline
\end{tabular}

The blue circle shows the bearing radial nominal clearance $(200 \mu \mathrm{m})$, referred to as clearance condition A. The green closed curve designates the clearances measured with the generator excited at $0 \mathrm{MW}$, during bearings special commissioning tests [10], nominated as condition B. The orange elliptical curve with crossed marks shows the clearances obtained by simulation using commercial software based on the Finite Volume Method (FVM), denoted as clearance condition C. The temperatures measured in the bearing bracket when the generator was operating at a steady-state condition with nominal load (700 MW) were used as boundary conditions in this simulation. Finally, the red outer curve defines the clearances measured at $700 \mathrm{MW}$, also during the cited bearing special commissioning tests [10], referred to as condition D. The significant dimensional changes when the generator is loaded are caused by the differential heating of bracket arms, originated by the electromagnetic field induced by the generator terminals, components (12) and (13) in Figure 1. This effect may have significant consequences but, usually, is disregarded by the most refined bearing models. It makes bearing anisotropic, with clearances much larger than the nominal values, decreasing the predicted bearing stiffness expressively [6]. The distribution of the pads clearances of a journal bearing may be evaluated using the pads temperatures measured at steady-state condition [9].

2.2. Some Remarks on LHG Models. The dynamic behavior of an LHG has a considerable dependence on the dynamic coefficients of journal bearings [11]. For the sake of convenience, 


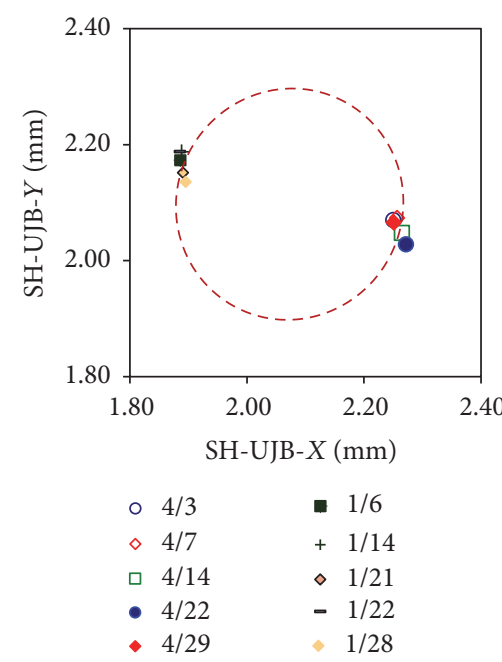

(a)

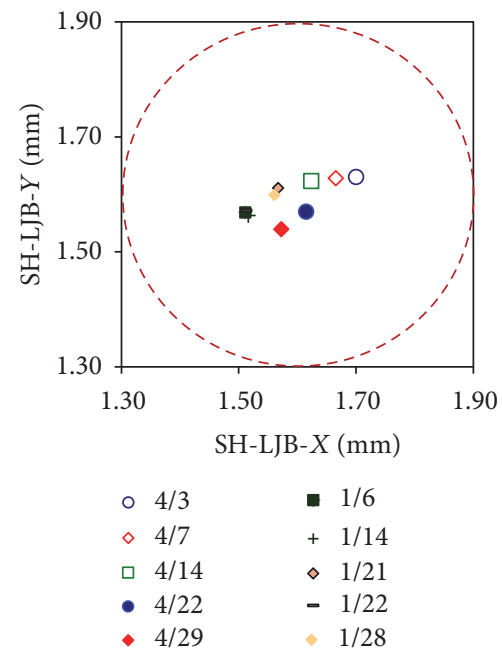

(b)

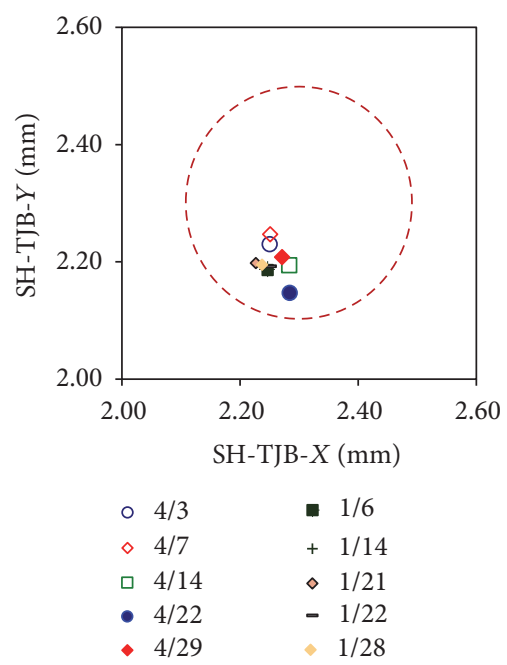

(c)

Figure 3: Shaft eccentricity in the upper (a), lower (b), and turbine (c) journal bearings of a 700 MW hydrogenerator, measured for several months.

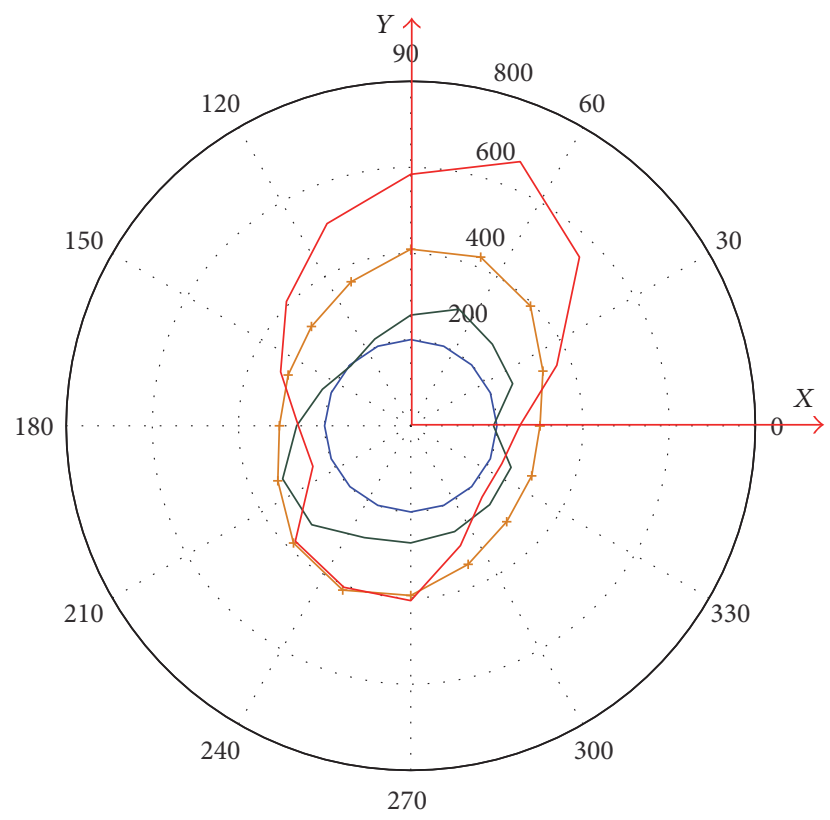

FIgURE 4: Pads clearances distribution $(\mu \mathrm{m})$ in the upper journal bearing of an LHG: (a) nominal: clearance condition A, blue circle; (b) measured at $0 \mathrm{MW}$ : condition $\mathrm{B}$, closed curve in green; (c) simulated at $700 \mathrm{MW}$ : condition C, crossed ellipse in orange; (d) measured at $700 \mathrm{MW}$ : condition D, outer closed curve in red.

in some cases, the dynamic coefficients are well-defined and fixed parameters $[12,13]$. However, it is well-known that bearing operating conditions (radial static load, viscosity, or clearance) have significant influence in the dynamic coefficients [6]. As LHG are vertical rotating machines, the radial static loads in the journal bearings are not predefined. For this reason, some references prescribe this load under different basis. For instance, in the dynamic analysis of Itaipu hydrogenerators, the manufacturer assumed that this load was $600 \mathrm{kN}$ when the generator is excited [14], independently of the generator power (Table 1 indicates that this load increases with the generator power and reaches approximately half of this value). Based on previous tests, Nässelqvist et al. [15] considered that the radial static load in the journal bearings of a $42 \mathrm{MW}$ hydrogenerator of vertical assembly was $30 \mathrm{kN}$.

In other references, the radial static load was measured using strain gauges installed in the bearing bracket arms [16] or in the pivot pins of the bearing pads [17]. This load may be also estimated using curves relating radial load with shaft eccentricity, calculated previously. In this case, the shaft eccentricity was estimated using the shaft relative vibration signals acquired in bearing orthogonal directions. The using of four proximity transducers instead of the usual two transducers arrangement, similarly to the procedure used in generator air gap monitoring, may improve this measurement accuracy [18].

Cardinali et al. [11] modeled a hydrogenerator in two different ways. The first way used a nonlinear model, where the equation of motion was solved simultaneously with the Reynolds equations of the journal bearings pads. The second way used a linear model, where the journal bearing dynamic coefficients were determined under the operating conditions that provide the highest coincidence between the characteristic frequencies of both linear and nonlinear models. Xu et al. [19] also used a nonlinear model, reducing the processing time by means of a database containing the journal bearings forces calculated previously for the several possible operating conditions.

Tiwari et al. [20] remark that "historically theoretical estimation of the dynamic bearing characteristics has always been a source of error in the prediction of rotor-bearing systems," mainly due to the difficulty of determining bearing operating conditions accurately. Both bearing radial static 
load and the resulting shaft eccentricity are used to characterize bearing operating conditions. Even in the more refined models, once the shaft eccentricity is determined, the pads clearances are calculated considering that the pivot point of all pads lies in a perfect circle. This means that the bearing housing is ideal, without the dimensional changes described in the previous section (Nässelqvist et al. [17] comment that the geometry of hydrogenerator bearing brackets "changes with temperature, as the generator temperature varies from between 15 and $80^{\circ} \mathrm{C}$," influencing "bearing clearances, which changes the relation between bearing properties"; however, apparently, no further investigations were done in this direction). Then bearing coefficients are determined, considering only the oil film hydrodynamic effects (hydrodynamic model) or considering the additional thermal effects from bearing losses (thermohydrodynamic or THD model) or with the deformation effects created by the oil film pressure (thermoelastohydrodynamic or TEHD model) [21]. Dimond et al. [21] highlight the needs of using TEHD models to theoretically determine the dynamic coefficients, remarking that even in this case the "agreement between theory and experiment for bearing coefficients is seldom better than 10-20 percent."

In most of the references, the journal bearing dynamic coefficients were obtained using Reynolds bearing model, solving Reynolds equation by the Finite Difference Method (FDM). Nevertheless, Xu et al. [19] used the BentlyMuszynska bearing model [22] and Wang et al. [23] solved Reynolds equation using an approximated analytical solution through the Variable Separation Method. LHG shafts are modeled using Bernoulli beam element [11] or Timoshenko beam element [19]. The Finite Element Method (FEM) was used in many of the recent articles, while the Transfer Matrix Method (TMM) is encountered in some older references $[14,24]$. In most cases the generator rotor and the turbine runner are modeled as rigid discs [11, 19]; their radial and axial elasticity are only considered in some cases [14]. The dynamic effects of turbine labyrinth seals are also considered only in a few references [11]. Some articles investigate the effects of magnetic pull in hydrogenerators dynamics [12]. However, the magnetic pull, in itself, is always modeled by a negative stiffness, which is usually determined by the generator manufacturer and depends on empirical coefficients, like the pole factor [25]. This stiffness depends on mainly the magnetic excitation of the generator and should have no significant influence of the generator power.

\section{Simplified Models to Assist Fault Detection and Diagnosis}

A mathematical model used to assist fault detection and fault diagnosis in a rotating machine usually requires less refinement than the models used during the design phase. For instance, at the design phase, the journal bearing model must predict adequately how bearing losses will influence oil film viscosity. However, this viscosity may be easily estimated during operation using the monitored temperatures of bearing pads and lubricant.

\subsection{Mathematical Model to Theoretically Estimate Bearing Stiffness}

3.1.1. Model Description. The frequent, unpredictable, and significant changes in the bearing operating conditions may make the more refined models to determine bearing stiffness useless. Anyway, many times it is necessary to estimate bearing stiffness for a well-defined operating condition. The elementary hydrodynamic model presented in Figure 5, a tilting pad journal bearing with plane surfaces, may be used in this case. This model uses the rectangular coordinates $x$ in the shaft sliding direction, $z$ in the shaft axial direction, and $y$ across the oil film thickness. Each bearing pad has length $\beta R$ and width $L$ and is supported by a pivot located at coordinates $(\alpha R, 0,0)$.

The oil film thickness is given by $y=h(x)$ when shaft and bearing are aligned with thicknesses $h_{\text {in }}$ at leading edge and $h_{\text {out }}$ at the trailing edge. A given point of shaft surface has velocities $u_{a}, v_{a}$, and $w_{a}$, respectively, at $x, y$, and $z$ directions. In the same order, a point of the pad surface has velocities $u_{b}$, $v_{b}$, and $w_{b}$. If pad velocities are negligible $\left(u_{b}=0, v_{b}=0\right.$, and $\left.w_{b}=0\right)$ and if shaft surface velocity is negligible at $z$ direction $\left(w_{a}=0\right)$, the oil film pressure $p=p(x, z)$ may be obtained by solving Reynolds equation, which is given by [26]

$$
\frac{\partial}{\partial x}\left(h^{3} \frac{\partial p}{\partial x}\right)+\frac{\partial}{\partial z}\left(h^{3} \frac{\partial p}{\partial z}\right)=6 \eta U \frac{\partial h}{\partial x}
$$

where $U$ is the shaft tangential velocity and $\eta$ is the lubricant dynamic viscosity.

It may be shown that the pad attitude $\left(n=h_{\text {in }} / h_{\text {out }}\right)$ for this bearing may be determined by the following equation [27]:

$$
\frac{\alpha}{\beta}=\frac{n(2+n) \ln n-(n-1)[2.5(n-1)+3]}{\left(n^{2}-1\right) \ln n-2(n-1)^{2}} .
$$

Equation (2) gives $n=2.775$ for the journal bearings of Itaipu generators $(\alpha / \beta=0.4)$. In this case, the linear oil film distribution is given by [28]

$$
h(x)=\frac{[(n-1) x+\beta R]}{[(n-1) \alpha R+\beta R]} c,
$$

where $c=h(x=\alpha R)$ is the pad clearance. The former equation has the advantage of determining the oil film thickness distribution directly, if the pad geometry $(\alpha R$ and $\beta R)$ and clearance $(c)$ are known, with no need of an iterative process to determine the pad attitude.

Figure 6 shows the oil film thickness measured (green crossed curve) over a pad of the upper journal bearing of a $700 \mathrm{MW}$ hydrogenerator operating at speed-no-load, during bearings special commissioning tests [10]. The oil film thickness was measured dynamically, using a proximity transducer installed in shaft collar. Therefore, this measurement contains errors due to shaft and pad vibrations. The measured pad clearance was $280 \mu \mathrm{m}, 40 \%$ higher than the nominal value. Figure 6 also shows the linear oil film thickness given by (3). 


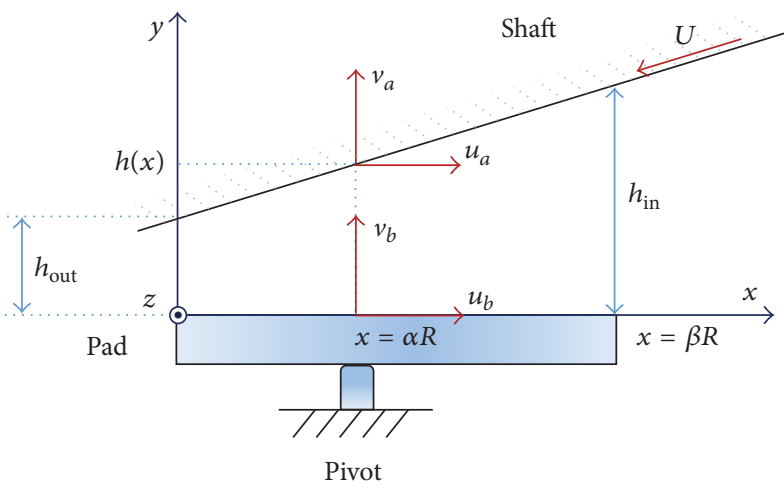

(a)

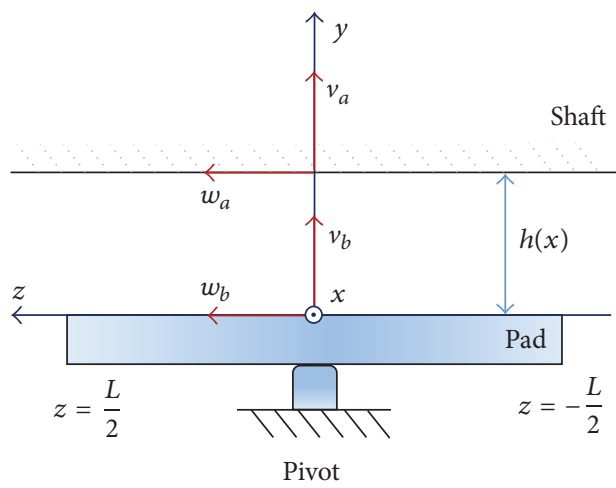

(b)

FIGURE 5: Elementary hydrodynamic model for LHG journal bearing: (a) view from axial direction; (b) view from sliding direction.

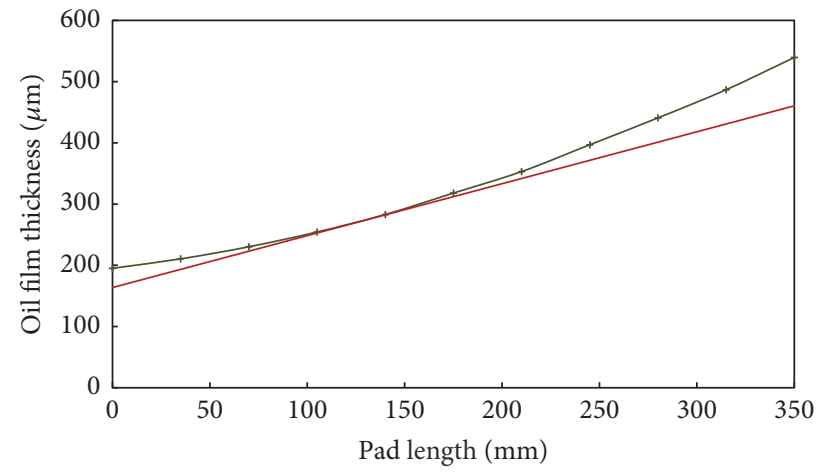

FIGURE 6: Measured (green) and linearized (red) distributions of the oil film thickness on pad 4 of the upper journal bearing of an LHG, at speed-no-load condition.

It may be also shown that the following equation is obtained when the Finite Difference Method (FDM) is used to solve Reynolds equation:

$$
\begin{aligned}
& p_{i, k}+A_{1 i, k} p_{i+1, k}+A_{2 i, k} p_{i-1, k}+A_{3 i, k} p_{i, k+1}+A_{4 i, k} p_{i, k-1} \\
& =B_{i, k},
\end{aligned}
$$

where $p_{i, k}$ is the pressure $p(x, z)$ at coordinates $x=i \Delta$ and $z=k \Delta$ and $\Delta$ is the dimension of square grid used. It also may be shown that the coefficients of (4) are given by

$$
\begin{aligned}
A_{1 i, k} & =-\left(\frac{1}{4}+\frac{3 a_{i} \Delta}{8 h_{i}}\right), \\
A_{2 i, k} & =-\left(\frac{1}{4}-\frac{3 a_{i} \Delta}{8 h_{i}}\right), \\
A_{3 i, k} & =-\frac{1}{4}, \\
A_{4 i, k} & =-\frac{1}{4}, \\
B_{i, k} & =-\frac{3 a_{i} \eta U \Delta^{2}}{2 h_{i}^{3}},
\end{aligned}
$$

where $h_{i}$ is the oil film thickness at $x=i \Delta$ and $a_{i}=d h(x=$ $i \Delta) / d x$. For a linearized oil film thickness, then $a_{i}$ is constant and is given by

$$
a_{i}=\frac{(n-1)}{[(n-1) \alpha R+\beta R]} c .
$$

Equation (4) may be solved for determining the oil film pressure distribution on all bearing pads, and these pressures may be integrated over the respective pad areas for determining the forces on the pads. These forces may be used to compute the total force $\mathbf{F}$ acting in the bearing, which is a function of shaft position and velocity. If the variations in the shaft coordinates $(X, Y)$ and velocities $\left(X^{\prime}, Y^{\prime}\right)$ are small, the total force components in two orthogonal directions $X\left(F_{X}\right)$ and $Y\left(F_{Y}\right)$ may be represented in a truncated Taylor series expansion as [6]

$$
\begin{aligned}
& F_{X}=F_{0 X}+\frac{\partial F_{X}}{\partial X} X+\frac{\partial F_{X}}{\partial Y} Y+\frac{\partial F_{X}}{\partial X^{\prime}} X^{\prime}+\frac{\partial F_{X}}{\partial Y^{\prime}} Y^{\prime} \\
& F_{Y}=F_{0 Y}+\frac{\partial F_{Y}}{\partial X} X+\frac{\partial F_{Y}}{\partial Y} Y+\frac{\partial F_{Y}}{\partial X^{\prime}} X^{\prime}+\frac{\partial F_{Y}}{\partial Y^{\prime}} Y^{\prime}
\end{aligned}
$$

where $F_{0 X}$ and $F_{0 Y}$ are the components of the total force acting in the bearing, in the shaft static equilibrium position. The former equation defines bearing stiffness $\left(k_{i j}\right)$ and damping coefficients $\left(c_{i j}\right)$ as

$$
\begin{gathered}
{\left[\begin{array}{ll}
k_{X X} & k_{X Y} \\
k_{Y X} & k_{Y Y}
\end{array}\right]=\left[\begin{array}{ll}
\frac{\partial F_{X}}{\partial X} & \frac{\partial F_{X}}{\partial Y} \\
\frac{\partial F_{Y}}{\partial X} & \frac{\partial F_{Y}}{\partial Y}
\end{array}\right],} \\
{\left[\begin{array}{ll}
c_{X X} & c_{X Y} \\
c_{Y X} & c_{Y Y}
\end{array}\right]=\left[\begin{array}{ll}
\frac{\partial F_{X}}{\partial X^{\prime}} & \frac{\partial F_{X}}{\partial Y^{\prime}} \\
\frac{\partial F_{Y}}{\partial X^{\prime}} & \frac{\partial F_{Y}}{\partial Y^{\prime}}
\end{array}\right] .}
\end{gathered}
$$

3.1.2. Model Validation. A MATLAB program was written to solve (4), determining the pressure on the bearing pads and the bearing stiffness coefficients given by (8). This program allows the use of prescribed clearance and oil film viscosity 


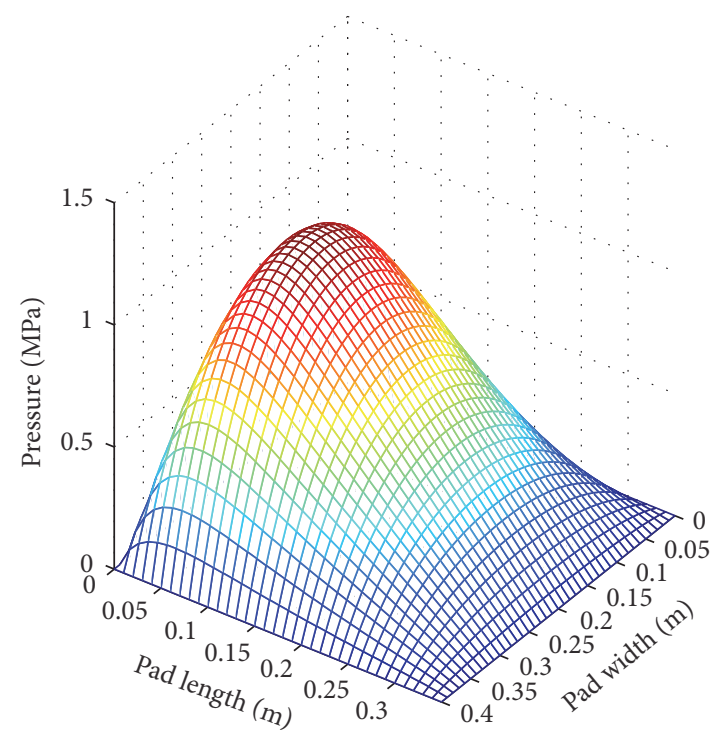

(a)

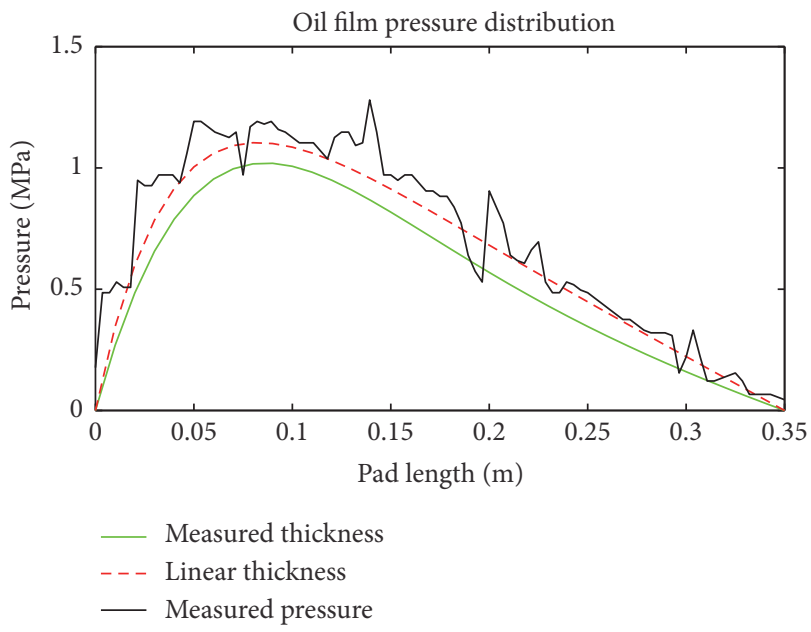

(b)

Figure 7: (a) Calculated 3D and (b) comparison between calculated and measured pressure distributions on upper journal bearing, with clearance of $280 \mu \mathrm{m}$ and a dynamic viscosity of 0.047 Pas (lubricant at $40^{\circ} \mathrm{C}$ ).

for each individual bearing pad, enabling the determination of bearing stiffness for all clearances conditions shown in Figure 4. Faults usually change bearing parameters, like clearance, load, and lubricant viscosity. Bearing stiffness and damping coefficients have similar sensitivity to the changes in these parameters [6]. Therefore, as already mentioned, this article has focused on bearing stiffness, as this coefficient is easier to estimate and to monitor for fault detection and diagnosis purposes.

The mentioned program was used to determine the oil film pressure distribution over a pad of the upper journal bearing of Itaipu hydrogenerators, with a clearance of $280 \mu \mathrm{m}$ and with an average viscosity of 0.047 Pas, the same values existing in a pad where the oil film pressure was measured [10]. The estimation of the oil film temperature and viscosity considered the results obtained by Daniel and Cavalca [29]. This bearing has 16 pads with length $\beta R=0.35 \mathrm{~m}$, width $L=$ $0.40 \mathrm{~m}, \alpha / \beta=0.40$, and radius $R=1.103 \mathrm{~m}$. The tangential velocity of shaft surface is $U=10.6 \mathrm{~m} / \mathrm{s}$, considering a $60 \mathrm{~Hz}$ hydrogenerator at nominal speed $(92.3 \mathrm{r} / \mathrm{min})$. Figure $7(\mathrm{a})$ shows the pressure distribution obtained using the oil film with linear thickness distribution, as given by (3). Figure 7(b) compares the theoretically estimated and the measured pressures at the center of the pad. The green and the red dashed curves show, respectively, the pressures calculated using the measured and the linearized oil film thickness distributions, both shown in Figure 6. The black curve shows the measured pressure. It is not clear if the fluctuations in the measured pressure are real or only noise. Surprisingly, the measured pressure is closer to the pressure calculated using the oil film with linear thickness distribution. The measured load on the pad was $69.8 \mathrm{kN}$, while the theoretical loads were $61.8 \mathrm{kN}$ $(-11 \%)$ for the linear and $53.0 \mathrm{kN}(-24 \%)$ for the measured oil film thickness. Anyway, the closeness of the three curves indicates a satisfactory accuracy for this elementary model, which may be explained by the adequate definition of bearing operating conditions.

The cited program also determines the journal bearing force components, $F_{X}$ and $F_{Y}$, for a given shaft eccentricity. Figure 8 shows these force components in the upper journal bearing, when the shaft eccentricity varied in the range from $-100 \mu \mathrm{m}$ to $+100 \mu \mathrm{m}$, in $5 \mu \mathrm{m}$ steps. For an adequate comparison with the calculations done by the hydrogenerator manufacturer, we used the nominal clearance $(200 \mu \mathrm{m})$ and a dynamic viscosity of 0.020 Pas. As expected for a tilting pad journal bearing [6], there are no cross-coupling effects; therefore, $k_{X Y}=k_{Y X}=0$. Figure 8 also indicates that forcedisplacement relationship is nonlinear, analogous to a hardening stiffness with cubic characteristics. A curve fitting gives $F_{X}=3.9010^{9}\left(X+5.9510^{7} X^{3}\right) \mathrm{N}$, with a coefficient of determination $R^{2}=0.9999$.

Figure 9 shows the main stiffness values $\left(k_{X X}\right.$ and $\left.k_{Y Y}\right)$ of the upper journal bearing achieved with the proposed model and those calculated by the manufacturer during the project [14], in relation to the radial static load in $X$ direction, under the same operating condition. Both models provide null cross-coupled stiffness $\left(k_{Y X}=k_{Y Y}=0\right)$. The manufacturer used an isoviscous model, considered that the resultant force in each pad passes through the pivot, and neglected deformations in bearing housing and pad supports. The computational method used to solve Reynolds equation was not identified (the manufacturer calculations give $k_{X X}=$ $11.80 \mathrm{GN} / \mathrm{m}$ and $k_{Y Y}=6.15 \mathrm{GN} / \mathrm{m}$, when the radial load is $600 \mathrm{kN}$ in $X$ direction; however, in the rotordynamic analysis of Itaipu hydrogenerators, the manufacturer considered that this bearing is isotropic, with an assumed stiffness of $k_{X X}=$ $\left.k_{Y Y}=6.67 \mathrm{GN} / \mathrm{m}\right)$. The satisfactory results presented in Figures 7(b) and 9 validate the proposed elementary hydrodynamic model for determining bearing stiffness, particularly 


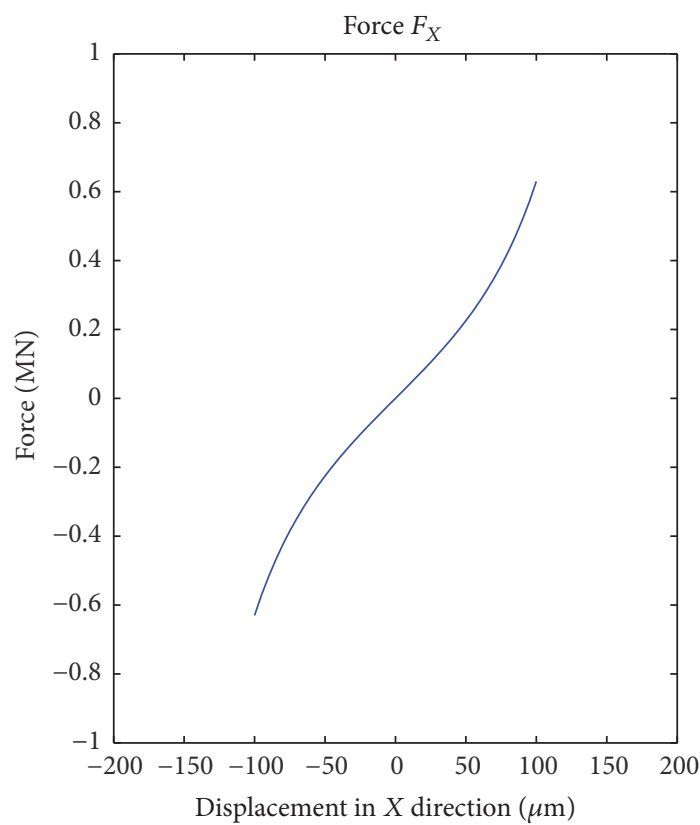

(a)

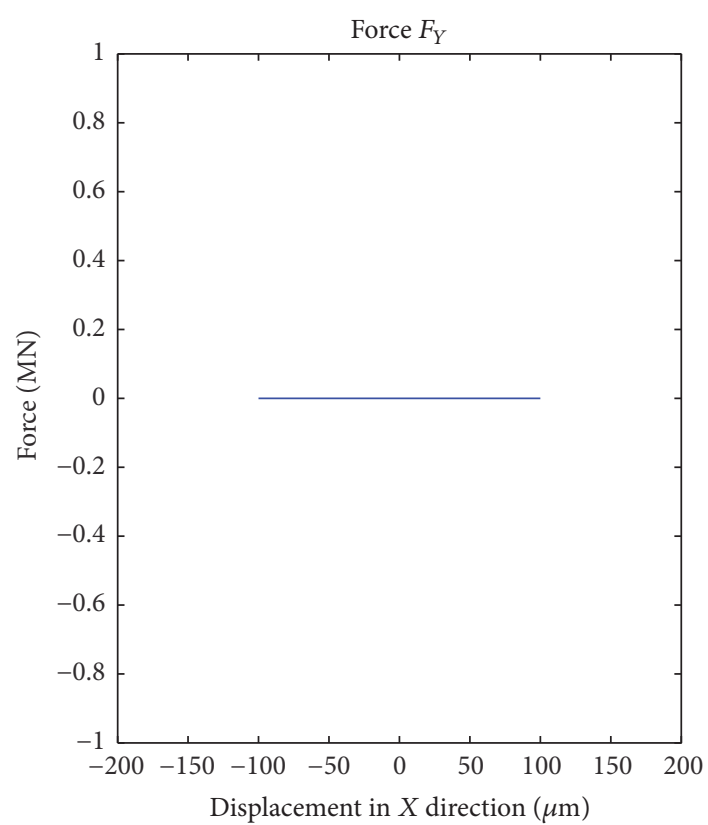

(b)

Figure 8: Upper journal bearing force components $\left(F_{X}\right.$ and $\left.F_{Y}\right)$ versus shaft displacement $X$ for $\eta=0.020$ Pas and $c=200 \mu \mathrm{m}$.

when bearing operating conditions are well-defined. Naturally, more advanced models may give more effective results, if the effects of the phenomena described in Section 2.1 are considered.

\subsection{Mathematical Model to Simulate the Dynamic Behavior of an $L H G$}

3.2.1. Model Description. The model described in the following simulates the dynamic behavior of LHG, giving as outputs the monitored six shaft relative vibrations in displacement, as well as the six bearing absolute vibrations expressed in velocity. This model may simulate the most frequent faults in LHG, under arbitrary excitations in the generator rotor and in the turbine runner, including unbalance forces. Figure 10 shows this simplified model, which divides an LHG into four bodies, the rotating part and the three journal bearings brackets. As LHG operate at subcritical speeds and as their shafts are much stiffer than their bearing brackets [14], the rotating part is considered a rigid body. The bearing brackets are also considered rigid bodies, with an effective mass equal to one-third of their total mass, as used by Cardinali [30], probably based on the effective mass of an oscillating spring [31]. This model considers the gyroscopic effect and the journal bearings anisotropy, with cross-coupling effects. It assumes that shaft relative vibrations are low enough to neglect the nonlinear effects of bearing stiffness. The effects of the thrust bearing axial stiffness in the lateral vibrations are considered, as this bearing is of Kingsbury type. However, thrust bearings with pads supported by elastic tanks, in normal operating conditions, have no influence in the LHG lateral vibrations [13].

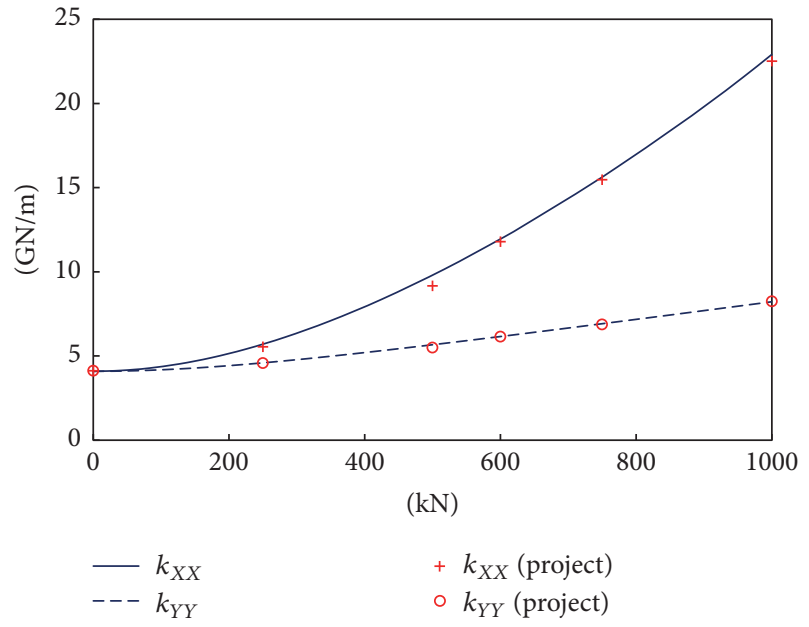

FIGURE 9: Upper journal bearing main stiffness values $\left(k_{X X}\right.$ and $\left.k_{Y Y}\right)$ achieved with the proposed method (continuous and dashed lines) and calculated by the manufacturer during the project ("+" and "。" marks), in relation to the radial static load in $X$ direction, for $\eta=$ 0.020 Pas and $\mathbf{c}=200 \mu \mathrm{m}$.

The rotating part has a constant angular velocity $\Omega$ around the $z$-axis (the angle around $z$-axis is determined by $\varphi_{z}(t)=\Omega t$, where $t$ is time), and it can make linear displacements in $X, Y$, and $Z$ directions, besides angular oscillations around $X\left(\varphi_{x}\right)$ and $Y\left(\varphi_{y}\right)$ directions. Bearing brackets can make linear displacements along the coordinates $x_{i}$ and $y_{i}(i=1$ for the upper journal bearing, $i=2$ for the lower journal bearing, and $i=3$ for the turbine journal bearing). Table 2 describes the main parameters of this model, whose values were obtained mainly in [14]. 
TABLE 2: Parameters of the Rigid Body Model.

\begin{tabular}{|c|c|c|c|}
\hline Symbol & Description & Unit & Value \\
\hline$m$ & Mass of LHG rotating part & $\mathrm{kg}$ & $2.37 E 6$ \\
\hline$J_{p}$ & Polar moment of inertia LHG of rotating part & $\mathrm{kgm}^{2}$ & $0.84 E 8$ \\
\hline$J_{d}$ & Diametral moment of inertia LHG of rotating part & $\mathrm{kgm}^{2}$ & $1.09 E 8$ \\
\hline$m_{1}$ & Upper journal bearing (UJB) effective mass & $\mathrm{kg}$ & $0.45 E 5$ \\
\hline$m_{2}$ & Lower journal bearing (LJB) effective mass & $\mathrm{kg}$ & $1.00 E 5$ \\
\hline$m_{3}$ & Turbine journal bearing (TJB) effective mass & $\mathrm{kg}$ & $0.80 E 5$ \\
\hline$k_{1 x x}, k_{1 y y}$ & UJB bearing main stiffness & $\mathrm{N} / \mathrm{m}$ & $7.17 E 9$ \\
\hline$k_{1 x y}=k_{1 y x}$ & UJB bearing cross-coupling stiffness & $\mathrm{N} / \mathrm{m}$ & $0.00 E 9$ \\
\hline$k_{2 x}, k_{2 y}$ & UJB bracket stiffness & $\mathrm{N} / \mathrm{m}$ & $1.18 E 9$ \\
\hline$k_{3 x x}, k_{3 y y}$ & LJB bearing main stiffness & $\mathrm{N} / \mathrm{m}$ & $4.29 E 9$ \\
\hline$k_{3 x y}=k_{3 y x}$ & LJB bearing cross-coupling stiffness & $\mathrm{N} / \mathrm{m}$ & $0.00 E 9$ \\
\hline$k_{4 x}, k_{4 y}$ & LJB bracket stiffness & $\mathrm{N} / \mathrm{m}$ & $2.22 E 9$ \\
\hline$k_{5 x x}, k_{5 y y}$ & TJB bearing main stiffness & $\mathrm{N} / \mathrm{m}$ & $6.67 E 9$ \\
\hline$k_{5 x y}=k_{5 y x}$ & TJB bearing cross-coupling stiffness & $\mathrm{N} / \mathrm{m}$ & $0.00 E 9$ \\
\hline$k_{6 x}, k_{6 y}$ & TJB bracket stiffness & $\mathrm{N} / \mathrm{m}$ & $2.13 E 9$ \\
\hline$k_{7 x}, k_{7 y}$ & Generator magnetic stiffness & $\mathrm{N} / \mathrm{m}$ & $-0.60 E 9$ \\
\hline$k_{8}$ & Thrust bearing axial stiffness & $\mathrm{N} / \mathrm{m}$ & $19.4 E 9$ \\
\hline$k_{9 x}, k_{9 y}$ & Turbine seals effective stiffness & $\mathrm{N} / \mathrm{m}$ & $5.00 E 7$ \\
\hline$l_{0}$ & Distance center of mass, center of generator rotor & $\mathrm{m}$ & 2.328 \\
\hline$l_{1}$ & Distance center of mass, center of UJB & $\mathrm{m}$ & 5.433 \\
\hline$l_{2}$ & Distance center of mass, center of LJB & $\mathrm{m}$ & 0.088 \\
\hline$l_{3}$ & Distance center of mass, center of TJB & $\mathrm{m}$ & 8.767 \\
\hline$l_{4}$ & Distance center of mass, center of turbine rotor & $\mathrm{m}$ & 12.577 \\
\hline$l_{5}$ & Distance center of mass, thrust bearing pivot & $\mathrm{m}$ & 2.113 \\
\hline
\end{tabular}

The total kinetic energy $T$ stored in the LHG may be determined as follows, using the rotation matrices that relate the inertial $(\mathbf{O} X, Y, Z)$ and the rotating $(\mathbf{C} x, y, z)$ coordinate systems:

$T$

$$
=T\left(\dot{X}, \dot{Y}, \dot{Z}, \varphi_{y}, \varphi_{z}, \dot{\varphi}_{x}, \dot{\varphi}_{y}, \dot{\varphi}_{z}, \dot{x}_{1}, \dot{y}_{1}, \dot{x}_{2}, \dot{y}_{2}, \dot{x}_{3}, \dot{y}_{3}\right) .
$$

In the former equation, the distance between the center of rotation and the center of mass of the LHG $(\epsilon)$ and the angular error between the rotation axis and the polar principal axis of inertia $(\chi)$ are parameters of the total kinetic energy. Other parameters are also the rotating mass $(m)$, the polar moment of inertia $\left(J_{p}\right)$, the diametral moment of inertia $\left(J_{d}\right)$, and the bearing effective masses $\left(m_{1}, m_{2}\right.$, and $\left.m_{3}\right)$. These parameters are shown in Figure 10 and described in Table 2. In the same way, the total potential energy $V$ stored in the LHG has the form

$$
V=V\left(X, Y, Z, \varphi_{x}, \varphi_{y}, x_{1}, y_{1}, x_{2}, y_{2}, x_{3}, y_{3}\right)
$$

All the bearings direct and cross-coupled stiffness, the bracket stiffness, the generator magnetic stiffness, and the stiffness of the turbine labyrinth seals, as well as the distances $\left(l_{0}\right.$ to $\left.l_{5}\right)$ shown in Figure 10, are all parameters of the potential energy.

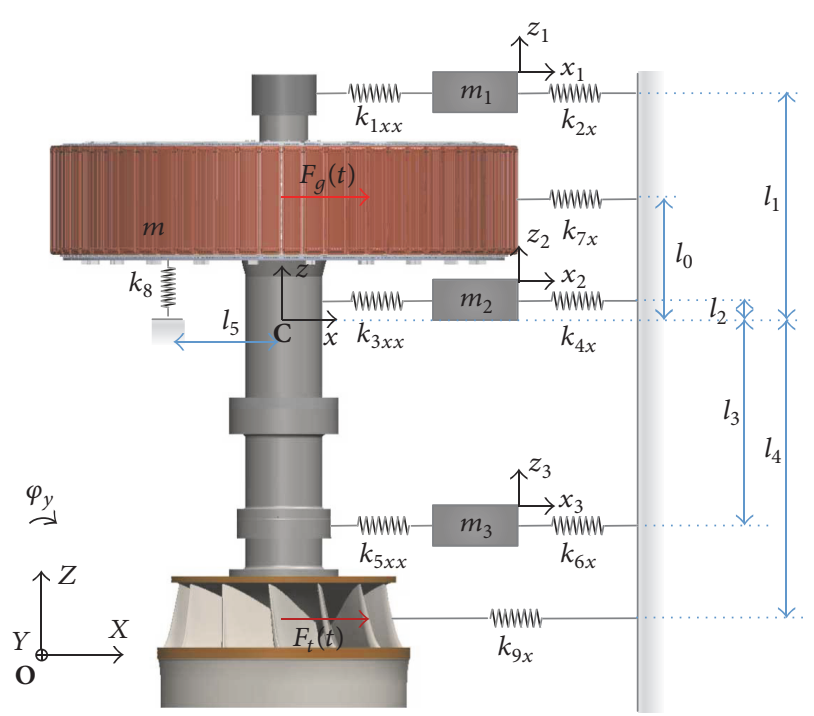

FIGURE 10: Simplified 10-DOF model to simulate LHG dynamic behavior.

This model considers that all the LHG damping is concentrated in the oil film of the journal bearings, not represented in Figure 10. The Rayleigh dissipation function is given by

$$
D=D\left(\dot{X}, \dot{Y}, \dot{\varphi}_{x}, \dot{\varphi}_{y}, \dot{x}_{1}, \dot{y}_{1}, \dot{x}_{2}, \dot{y}_{2}, \dot{x}_{3}, \dot{y}_{3}\right) \text {. }
$$


TABLE 3: Shaft relative vibrations measured by proximity transducers (in displacement) and bearing absolute vibrations measured by piezoelectric accelerometers and integrated by charge amplifiers (in velocity).

\begin{tabular}{lcccc}
\hline Journal bearing & \multicolumn{2}{c}{ Shaft relative vibrations } & \multicolumn{2}{c}{ Bearing absolute vibrations } \\
& $X$ direction & $Y$ direction & $X$ direction & $\dot{x}_{1}$ \\
\hline Upper bearing & $X+l_{1} \varphi_{y}-x_{1}$ & $Y-l_{1} \varphi_{x}-y_{1}$ & $\dot{x}_{2}$ & $\dot{y}_{1}$ \\
Lower bearing & $X+l_{2} \varphi_{y}-x_{2}$ & $Y-l_{2} \varphi_{x}-y_{2}$ & $\dot{x}_{3}$ & $\dot{y}_{2}$ \\
Turbine bearing & $X-l_{3} \varphi_{y}-x_{3}$ & $Y+l_{3} \varphi_{x}-y_{3}$ & $\dot{y}_{3}$ \\
\hline
\end{tabular}

Besides the bearing damping coefficients $\left(c_{i x}, c_{i y}\right.$ with $i=$ $1,2,3)$, the distances $\left(l_{0}\right.$ to $\left.l_{5}\right)$ shown in Figure 10 are also parameters of the Rayleigh dissipation function.

The LHG equation of motion is determined using Lagrange equation, which is given as [32]

$$
\begin{array}{r}
\frac{d}{d t}\left(\frac{\partial T}{\partial \dot{q}_{j}}\right)-\frac{\partial T}{\partial q_{j}}+\frac{\partial D}{\partial \dot{q}_{j}}+\frac{\partial V}{\partial q_{j}}=Q_{j}, \\
j=1,2,3, \ldots, 10,
\end{array}
$$

where the generalized forces $Q_{j}$ are

$$
Q_{j}=\sum_{l} \mathbf{F}_{l} \cdot \frac{\partial \mathbf{r}_{l}}{\partial q_{j}}+\sum_{l} \mathbf{M}_{l} \cdot \frac{\partial \boldsymbol{\omega}_{l}}{\partial \dot{q}_{j}}
$$

In the former equation, $\mathbf{F}_{l}$ and $\mathbf{M}_{l}$ are the forces and moments vectors externally applied to body $l$, where $\mathbf{r}_{l}$ is the position where force $\mathbf{F}_{l}$ is applied and $\boldsymbol{\omega}_{l}$ is the angular velocity of this body around the axis of application of moment $\mathbf{M}_{l}$. As thrust bearing pads are evenly distributed and loaded, the axial displacement $Z$ may be decoupled from the other coordinates $[33,34]$. Once $\varphi_{z}$ is known, monitored shaft relative and bearing absolute vibrations may be determined by a 10-DOF model, represented by the following equation [34]:

$$
\mathbf{M} \ddot{\mathbf{x}}+\mathbf{C} \dot{\mathbf{x}}+\mathbf{G} \dot{\mathbf{x}}+\mathbf{K x}=\mathbf{F}(t),
$$

where $\mathbf{M}$ is the mass matrix, $\mathbf{C}$ is the damping matrix, $\mathbf{G}$ is the matrix of the gyroscopic effect, and $\mathbf{K}$ is the stiffness matrix. Also, in the former equation, $\mathbf{x}$ is the generalized coordinates vector and $\mathbf{F}(t)$ is the generalized forces vector.

Equation (14) may be represented in the state-space as follows:

$$
\begin{aligned}
\left\{\begin{array}{c}
\dot{\mathbf{x}}(t) \\
\ddot{\mathbf{x}}(t)
\end{array}\right\}= & {\left[\begin{array}{cc}
\mathbf{0} & \mathbf{I} \\
-\mathbf{M}^{-1} \mathbf{K} & -\mathbf{M}^{-1}(\mathbf{C}+\mathbf{G})
\end{array}\right]\left\{\begin{array}{l}
\mathbf{x}(t) \\
\dot{\mathbf{x}}(t)
\end{array}\right\} } \\
& +\left[\begin{array}{c}
\mathbf{0} \\
\mathbf{M}^{-1}
\end{array}\right] \mathbf{F}(t),
\end{aligned}
$$

where $\mathbf{0}$ is a square zero matrix and $\mathbf{I}$ is the identity matrix, both of order 10. A MATLAB program was written to solve the former equation, using an output matrix that provides the output vector of the state equation containing the shaft relative vibrations in displacement, as measured by the proximity transducers installed in the bearing pads support. The output vector also contains the bearing absolute vibrations in velocity, avoiding numerical differentiations or integrations for the comparison with the measured vibrations. Table 3 shows these vibration signals expressed using the coordinates shown in Figure 10.
3.2.2. Model Validation. The results obtained with simulations using this 10-DOF Rigid Body Model are compared following the results of two other simulations, used as references. The first group of references is formed by the simulations made by the manufacturer of Itaipu hydrogenerators, using the Transfer Matrix Method (TTM). The main results of these simulations are described in [14]. The second group of references consists of simulations using RotMEF, software based on the FEM developed by CEPEL (Electrical Energy Research Center), to make the rotordynamic analysis of power generating units, but with an emphasis on vertical hydrogenerators. In these simulations, the generator lower shaft and the turbine shaft were modeled as a single hollow shaft, with 11.5 meters length, with inner and outer diameters of 2.10 and 2.60 meters, respectively. Both this shaft and the generator upper shaft (2.80 meters long, with inner and outer diameters of 1.35 and 2.20 meters) were modeled as Timoshenko beams. Turbine runner and generator rotor were modeled as cylinders with the same height, mass, and polar moment of inertia. The dynamic coefficients of the journal bearings, thrust bearing, and turbine labyrinth seals, as well as the generator magnetic stiffness, were used with the same values in all the described simulations.

Table 4 shows the first four natural frequencies obtained in the three simulations, with the generator unexcited $\left(k_{7 x}=\right.$ $\left.k_{7 y}=0\right)$ and excited $\left(k_{7 x}=k_{7 y}=-0.60 \mathrm{GN} / \mathrm{m}\right)$. These natural frequencies may be stratified in three relatively close layers; the TMM natural frequencies are in the lower layer, the Rigid Body Model frequencies are in the upper layer, while the RotMEF natural frequencies are in the middle layer, near the average value of the natural frequencies. The three simulations showed similar vibration modes and Figure 11 shows the results obtained with the Rigid Body Model when the generator is excited. The simulations using the TMM and the Rigid Body Model indicated practically the same position for the nodes of the first two modes, whereas RotMEF indicated these nodes are displaced upwards, in about $15 \%$ of the $700 \mathrm{MW}$ hydrogenerator height.

In addition to the similarity of the theoretical results, the first two natural frequencies obtained using the Rigid Body Model with the generator excited $(4.71$ and $5.12 \mathrm{~Hz}$ ) are close to the natural frequencies measured in an LHG in operation, 4.85 and $5.25 \mathrm{~Hz}$ at $530 \mathrm{MW}$ and 5.50 and $5.75 \mathrm{~Hz}$ at $540 \mathrm{MW}$ [35]. All these results indicate the Rigid Body Model may be used to assist vibration monitoring of LHG (the natural frequencies obtained using the Rigid Body Model are similar to the frequencies obtained by the other two methods because LHG is a subcritical rotating machine that operates at speeds 


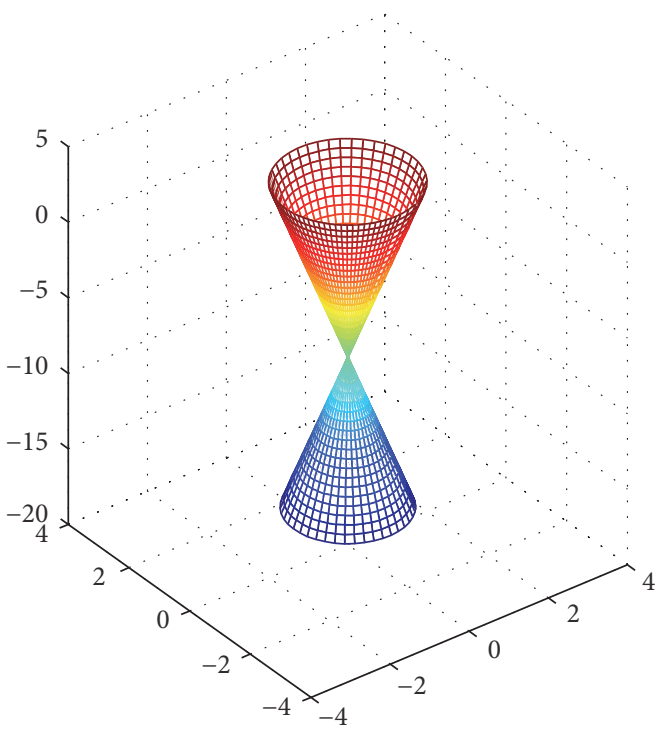

(a)

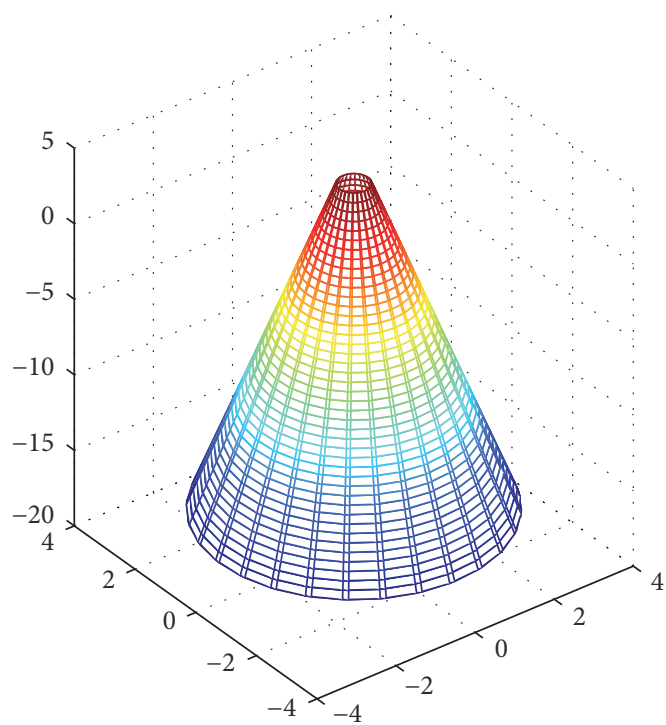

(c)

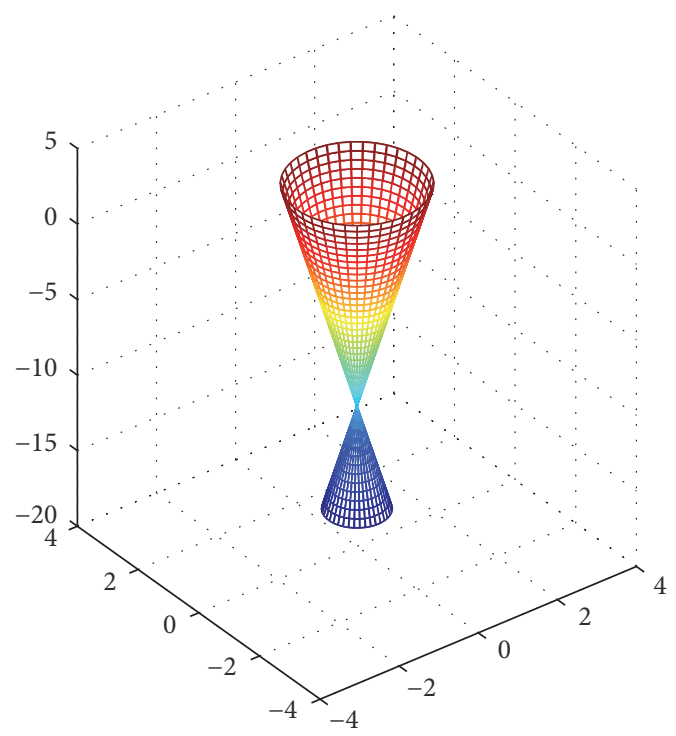

(b)

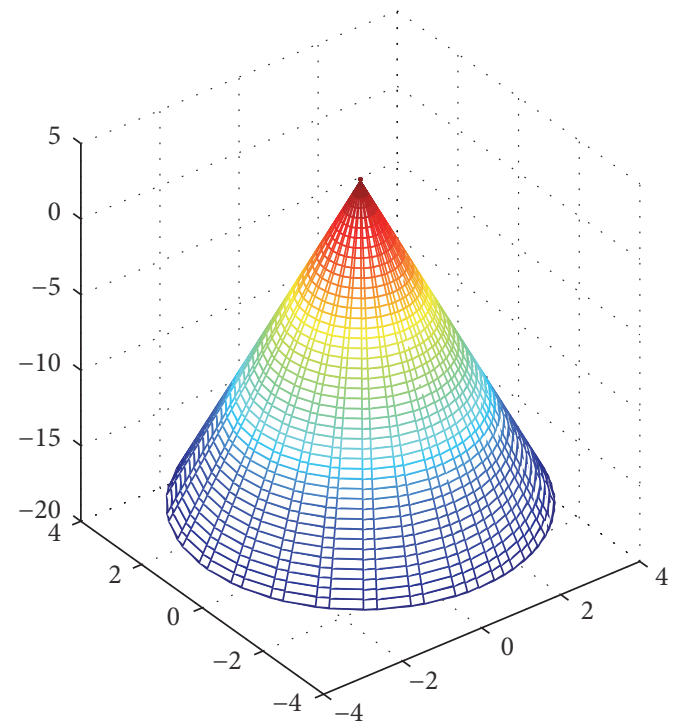

(d)

FIGURE 11: Vibration modes obtained with the Rigid Body Model, with the generator excited: (a) 1st mode (backward precession at 4.71 Hz); (b) 2nd mode (direct precession at $5.12 \mathrm{~Hz}$ ); (c) 3rd mode (backward precession at $7.18 \mathrm{~Hz}$ ); (d) 4th mode (direct precession at $7.91 \mathrm{~Hz}$ ).

TABLE 4: Comparison of the natural frequencies of Itaipu LHG obtained by the manufacturer Transfer Matrix Method (TMM), using the software RotMEF and using the Rigid Body Model, with the generator unexcited and excited.

\begin{tabular}{|c|c|c|c|c|c|}
\hline \multirow{2}{*}{ Generator operating condition } & \multirow{2}{*}{ Mathematical model } & \multicolumn{4}{|c|}{ Natural frequencies [Hz] } \\
\hline & & 1st mode & 2nd mode & 3rd mode & 4th mode \\
\hline \multirow{3}{*}{ Unexcited } & Manufacturer (TMM) & 4.46 & 4.95 & 5.80 & 6.91 \\
\hline & RotMEF (FEM) & 4.40 & 5.47 & 6.94 & 7.31 \\
\hline & Rigid Body Model & 5.24 & 5.74 & 7.28 & 7.93 \\
\hline \multirow{3}{*}{ Excited } & Manufacturer (TMM) & 3.79 & 4.05 & 5.56 & 6.90 \\
\hline & RotMEF (FEM) & 4.05 & 4.89 & 6.63 & 7.22 \\
\hline & Rigid Body Model & 4.71 & 5.12 & 7.18 & 7.91 \\
\hline
\end{tabular}


TABLE 5: Upper journal bearing direct and cross-coupled stiffness, for several clearances conditions, with viscosity $\eta=0.035$ Pas.

\begin{tabular}{|c|c|c|c|c|c|c|}
\hline \multirow{2}{*}{ Clearance condition } & \multirow{2}{*}{ Clearance condition } & \multirow{2}{*}{$\begin{array}{l}\text { Coordinates } \\
(X, Y)[\mu \mathrm{m}]\end{array}$} & \multicolumn{4}{|c|}{ Bearing stiffness $[\mathrm{GN} / \mathrm{m}]$} \\
\hline & & & $k_{x x}$ & $k_{x y}$ & $k_{y x}$ & $k_{y y}$ \\
\hline A & Nominal clearance (shaft eccentricity $\epsilon=0 \mu \mathrm{m}$ ) & $(0,0)$ & 7.17 & 0.00 & 0.00 & 7.17 \\
\hline $\mathrm{A}^{*}$ & Nominal clearance (shaft eccentricity $\epsilon=67 \mu \mathrm{m})$ & $(67,0)$ & 11.8 & 0.00 & 0.00 & 8.55 \\
\hline B & Measured speed-no-load & $(0,0)$ & 4.10 & -0.71 & -0.71 & 3.43 \\
\hline $\mathrm{C}$ & Simulated at nominal load & $(0,0)$ & 1.69 & -0.18 & -0.18 & 1.13 \\
\hline $\mathrm{D}$ & Measured at nominal load & $(0,0)$ & 2.55 & -0.37 & -0.37 & 1.15 \\
\hline
\end{tabular}

The symbol " $*$ "indicates that the shaft position is different. In the clearance condition A the pad clearances are in the nominal values $(200 \mu \mathrm{m})$ and the shaft is centered at coordinates $(0,0)$. In clearance condition $\mathrm{A}^{*}$ the pad clearances are once more in the nominal values but the shaft has an eccentricity of $67 \mu \mathrm{m}$.

far below the first critical speed; however, the Rigid Body Model overestimates LHG critical speeds and it shall not be used for this purpose). Again, it is important to remark that more advanced models may give more effective results only if the effects of the phenomena described in Section 2.1 are considered.

\section{Applications of the Simplified Models and Discussion of the Results}

4.1. Effects of Pad Clearances Distributions in the Bearing Stiffness. Table 5 shows the upper journal bearing stiffness determined for the clearances conditions A to D, as shown in Figure 4. This table indicates that bearing stiffness may vary significantly with the change in shaft eccentricity. For instance, a shaft eccentricity of $67 \mu \mathrm{m}$ in $X$ direction, equivalent to one-third of the bearing radial nominal clearance, increases bearing stiffness in approximately 65\%. Table 5 also shows that the large clearances with uneven distribution decrease bearing stiffness to a quarter of its nominal value or less and create cross-coupling effects in the anisotropic bearing. The influence of these effects in the LHG dynamics is shown in the following sections.

4.2. Effects of Bearing Parameters in the Bearing Stiffness. Simulations with the model described in Section 3.1 have shown that bearing stiffness is directly proportional to the shaft speed and to the lubricant viscosity, even when the distribution of bearing clearances becomes elliptical, due to bearing housing dimensional changes. Due to the well-known relationship between the viscosity and the temperature of lubricant oil, the bearing stiffness decreases exponentially with the lubricant temperature increase. Figure 12 shows the variation of the upper journal bearing stiffness with the lubricant temperature when the bearing has clearance condition C. All the direct and cross-coupled bearing stiffness values have the same dependence on the lubricant temperature.

Figure 13 shows the variation of the upper journal bearing stiffness with the proportional variation of the relative clearance when the journal bearing has a clearance elliptical distribution proportional to clearance condition C (in Figure 13, c is the pad clearance and $c_{\text {ref }}$ is the reference pad clearance, measured when the bearing had clearance condition $\mathrm{C}$, as shown in Figure 4). All the direct and cross-coupled bearing stiffness values decrease with the third power of the bearing

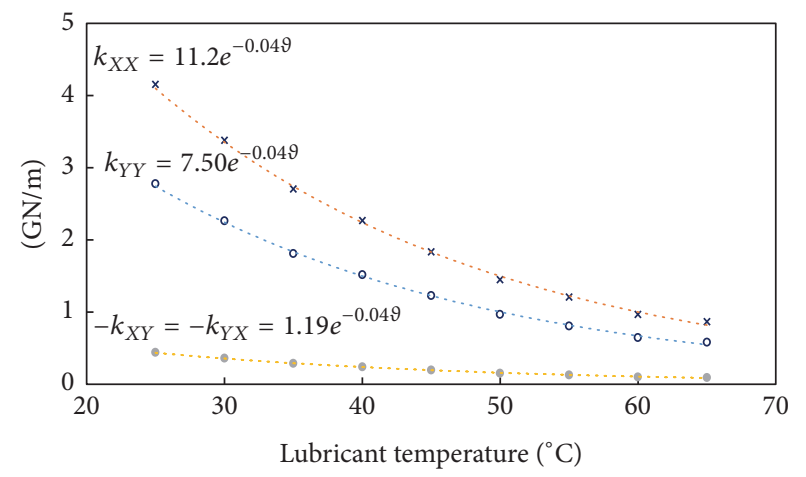

FIGURE 12: Variation of upper journal bearing stiffnesses with lubricant temperature $\vartheta$ (clearance condition $\mathrm{C}$ ).

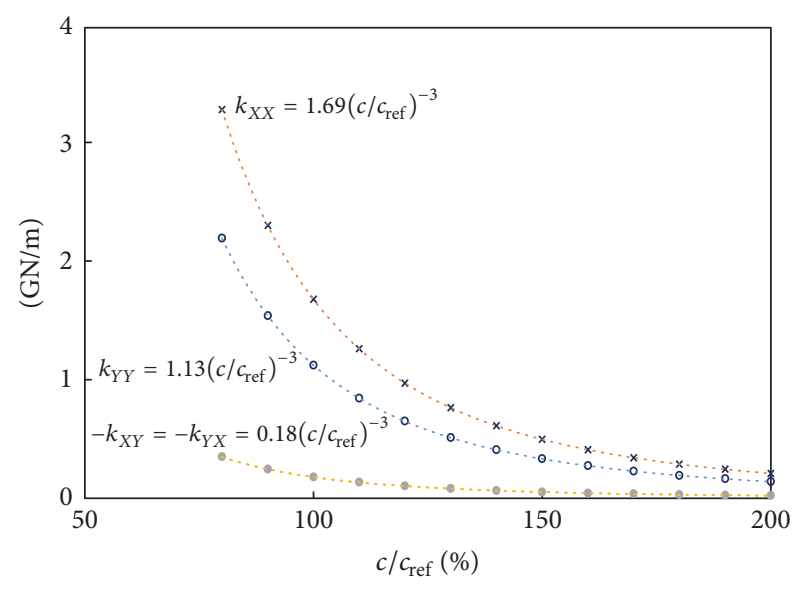

FIGURE 13: Variation of the upper journal bearing stiffness with the pads clearance (clearance condition $\mathrm{C}$ ).

clearance increase. These simulations have shown that the lubricant temperature and the bearing clearance have a major influence in bearing stiffness and, consequently, in the dynamic behavior of LHG.

4.3. Effects of Pad Clearances Distributions in Shaft and Bearing Vibrations. Table 6 shows the shaft relative and the bearing absolute vibrations obtained in simulations with the generator rotor unbalanced with ISO quality grade G4.25, using the five bearing stiffness values shown in Table 5. In 
TABLE 6: Simulated shaft and bearing vibrations at upper (UJB), lower (LJB), and turbine journal bearings (TJB), with the LHG at speed-noload (SNL) or excited, with generator rotor unbalanced (ISO grade G4.25).

\begin{tabular}{|c|c|c|c|c|c|c|c|c|c|c|c|c|}
\hline \multirow{3}{*}{ Clearance condition } & \multicolumn{6}{|c|}{ 1x shaft relative vibrations [ $\mu \mathrm{m}$ peak] } & \multicolumn{6}{|c|}{ 1x bearing absolute vibrations $[\mathrm{mm} / \mathrm{s}$ peak] } \\
\hline & \multicolumn{2}{|c|}{ UJB } & \multicolumn{2}{|c|}{ LJB } & \multicolumn{2}{|c|}{ TJB } & \multicolumn{2}{|c|}{ UJB } & \multicolumn{2}{|c|}{ LJB } & \multicolumn{2}{|c|}{ TJB } \\
\hline & Dir. $X$ & Dir. $Y$ & Dir. $X$ & Dir. $Y$ & Dir. $X$ & Dir. $Y$ & Dir. $X$ & Dir. $Y$ & Dir. $X$ & Dir. $Y$ & Dir. $X$ & Dir. $Y$ \\
\hline $\mathrm{A}(\mathrm{SNL})$ & 3.8 & 3.8 & 7.2 & 7.2 & 3.1 & 3.1 & 0.22 & 0.22 & 0.14 & 0.14 & 0.10 & 0.10 \\
\hline $\mathrm{A}^{*}(\mathrm{SNL})$ & 2.2 & 3.1 & 4.6 & 6.2 & 3.0 & 3.1 & 0.22 & 0.22 & 0.15 & 0.14 & 0.09 & 0.09 \\
\hline $\mathrm{B}(\mathrm{SNL})$ & 7.2 & 9.2 & 12 & 14 & 3.4 & 3.6 & 0.24 & 0.24 & 0.13 & 0.12 & 0.11 & 0.11 \\
\hline B (excited) & 10 & 13 & 16 & 20 & 4.0 & 4.3 & 0.32 & 0.35 & 0.17 & 0.16 & 0.12 & 0.13 \\
\hline C (excited) & 29 & 55 & 36 & 59 & 5.5 & 6.9 & 0.40 & 0.50 & 0.16 & 0.17 & 0.17 & 0.21 \\
\hline D (excited) & 19 & 57 & 25 & 61 & 4.8 & 7.0 & 0.35 & 0.51 & 0.16 & 0.17 & 0.15 & 0.21 \\
\hline
\end{tabular}

The symbol " $*$ "indicates that the shaft position is different. In the clearance condition A the pad clearances are in the nominal values ( $200 \mu \mathrm{m})$ and the shaft is centered at coordinates $(0,0)$. In clearance condition $A^{*}$ the pad clearances are once more in the nominal values but the shaft has an eccentricity of $67 \mu \mathrm{m}$.

the first three simulations, the hydrogenerator was in speedno-load (SNL) condition, with $k_{7 x}=k_{7 y}=0$. In the remaining three simulations, the generator was excited, with $k_{7 x}=$ $k_{7 y}=-0.60 \mathrm{GN} / \mathrm{m}$. For simplicity, it was considered that the lower journal bearing stiffness varied in a proportional manner to the upper bearing stiffness variation. The turbine bearing stiffness was kept constant at the nominal value, as this bearing is away from the influence of the generator electromagnetic field.

Table 6 shows that, in these conditions, the generator rotor unbalance affects mainly the generator journal bearings; the influences in the shaft and bearing vibrations are much lower at the turbine journal bearing. This table also indicates that, at the speed-no-load condition, the shaft vibrations obtained in the generator bearings with the measured clearances (condition B at SNL) are practically the double of the vibrations determined with the nominal clearances (condition A at SNL). This is an example of the prediction errors mentioned by Tiwari et al. [20]. Table 6 shows that shaft relative and bearing absolute vibrations may increase up to $40 \%$ when the generator is excited. Also, this table shows that shaft relative vibrations are more sensitive to the changes in bearing stiffness compared to bearing absolute vibrations.

4.4. Effects of Pad Clearances Distributions in the Natural Frequencies. Table 7 shows the effects of pad clearances distributions in the natural frequencies of the LHG rotating part. The calculations were performed with and without the generator magnetic stiffness, with bearings stiffness in the same conditions described in Table 5. The natural frequencies of the first and second modes are more susceptible to the changes in clearance distribution and bearing stiffness, especially the frequencies of the backward precession mode. These natural frequencies are also more susceptible to the effects of the generator magnetic stiffness. In both situations, the natural frequencies of the third and fourth modes are much less sensitive to changes.

4.5. Effects of Bracket Stiffness in the Natural Frequencies. Bearing stiffness may vary significantly, in normal operating conditions or with the advent of several types of faults in the LHG. Bracket stiffness may change only in the last condition,

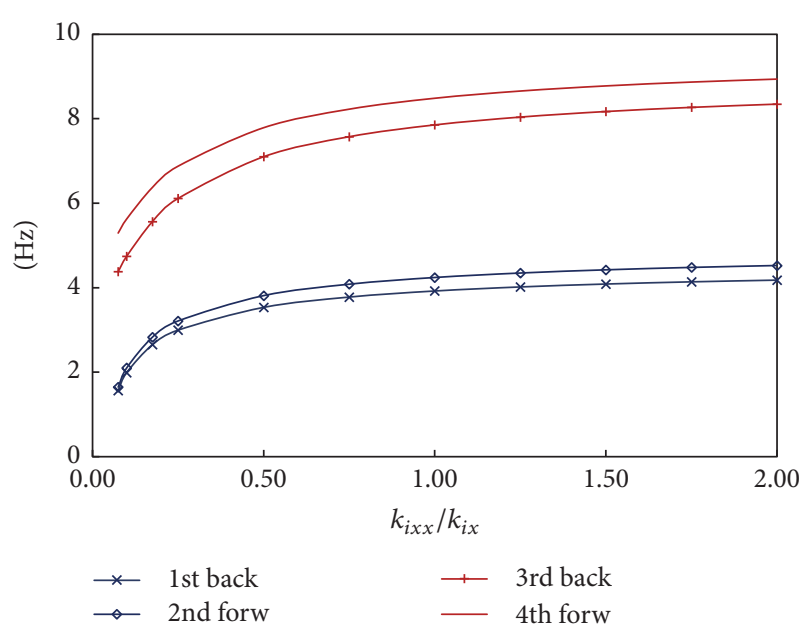

FIGURE 14: Natural frequencies of LHG rotor in function of the rate between bearing stiffness and bracket stiffness.

in the occurrence of some specific faults. Figure 14 shows the variation of the first four LHG natural frequencies in relation to the rate between bearing stiffness and bracket stiffness $\left(k_{i x x} / k_{i x}\right)$. Again, for simplicity, it was considered that this rate varied equally for the three journal bearings, which were considered isotropic $\left(k_{i x x}=k_{i y y}\right)$. This figure shows that natural frequencies practically do not change for high rates $\left(k_{i x x} / k_{i x}>1.5\right)$, and once in this range the brackets stiffness dominates the LHG dynamics. On the other hand, when bearing stiffness is lower than bracket stiffness, the mentioned dynamics are expressively affected by variations in the stiffness rate.

4.6. Simulations with the LHG Model. Figure 15 shows the shaft relative and the bearing absolute vibrations measured in $X$ direction of the upper journal bearing of an LHG, which was operating at speed-no-load and steady-state conditions when the generator rotor had an unbalance ISO quality grade G4.25. Figure 16 shows the same signals but measured at the lower journal bearing. On both figures, the upper diagrams show the vibration signals in time domain, acquired during 90 seconds with a sampling frequency of $600 \mathrm{~Hz}$. 


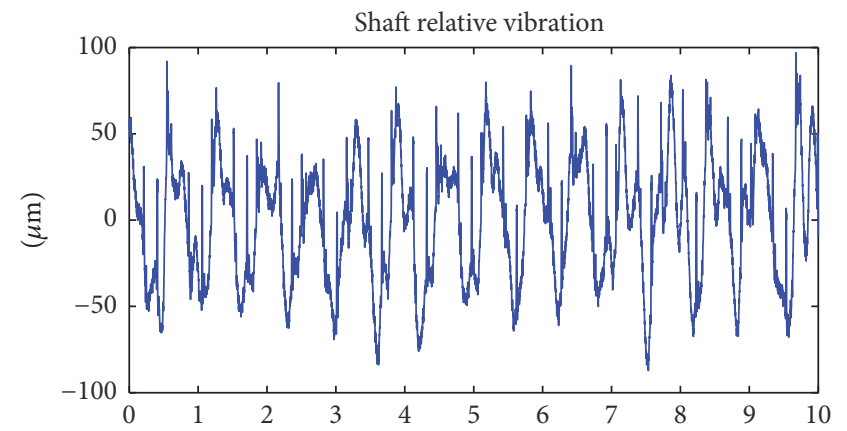

(s)

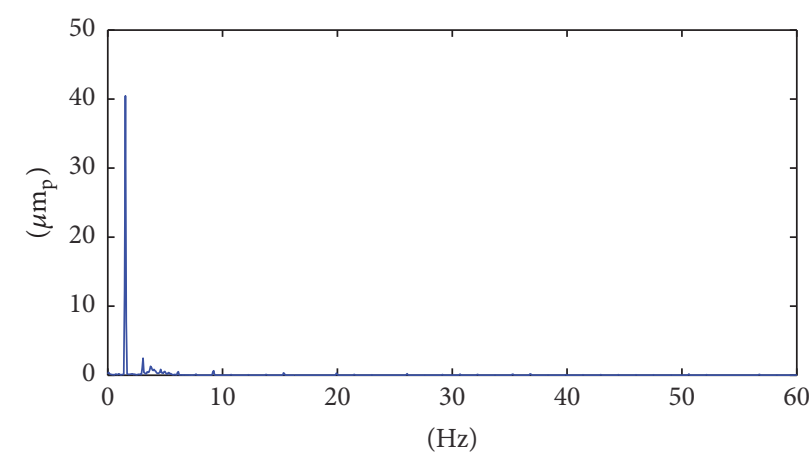

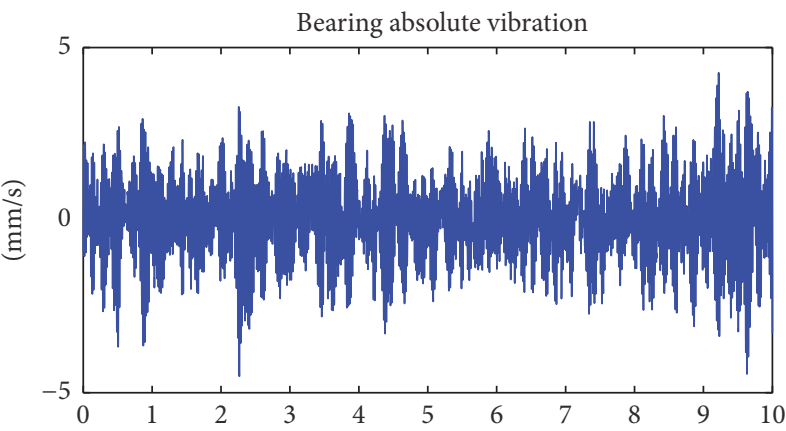

(s)

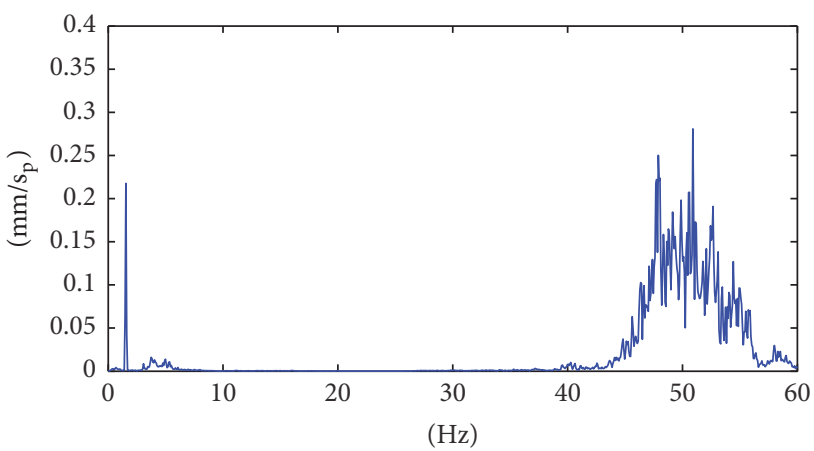

FIGURE 15: Measured shaft relative and bearing absolute vibrations at $X$ direction of the upper journal bearing, when generator rotor had an unbalance G4.25.

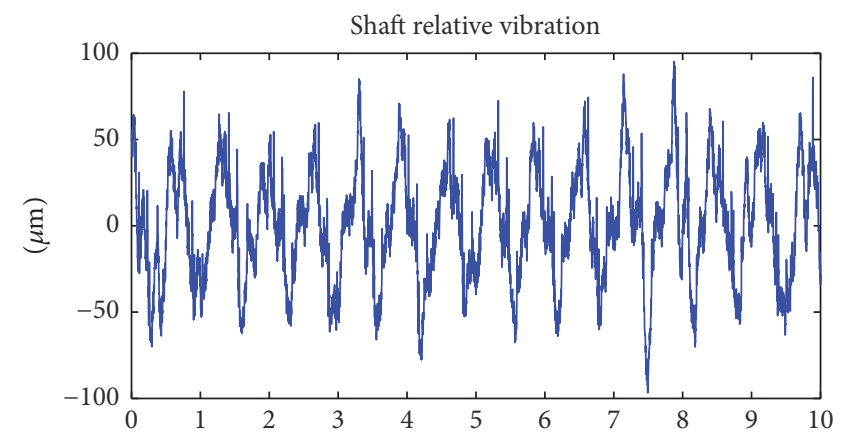

(s)

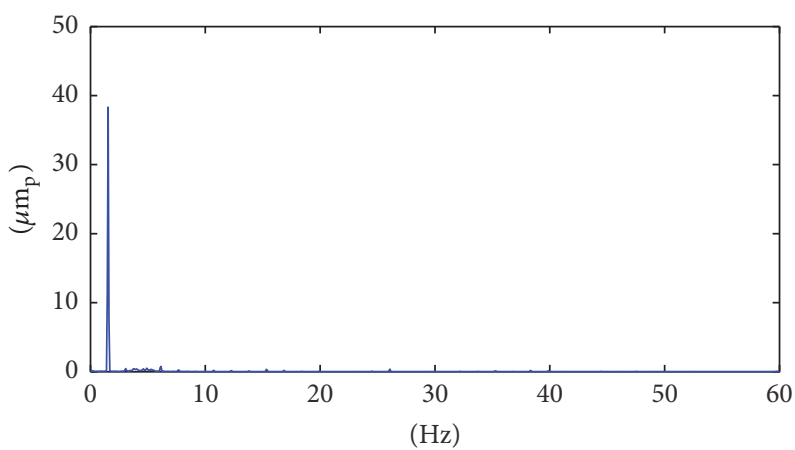

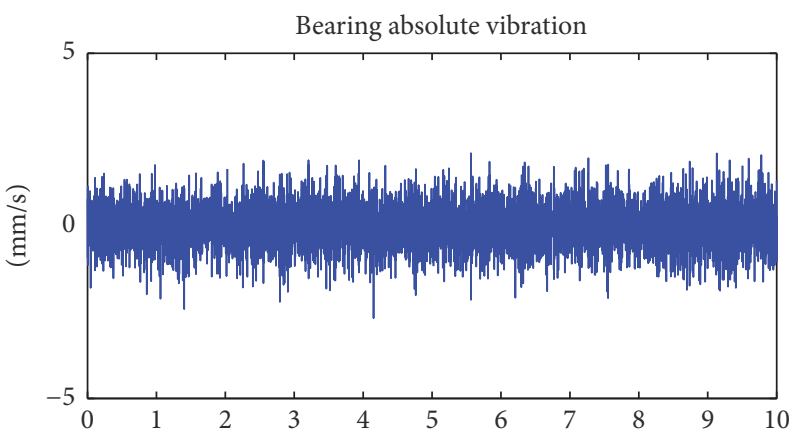

$(\mathrm{s})$

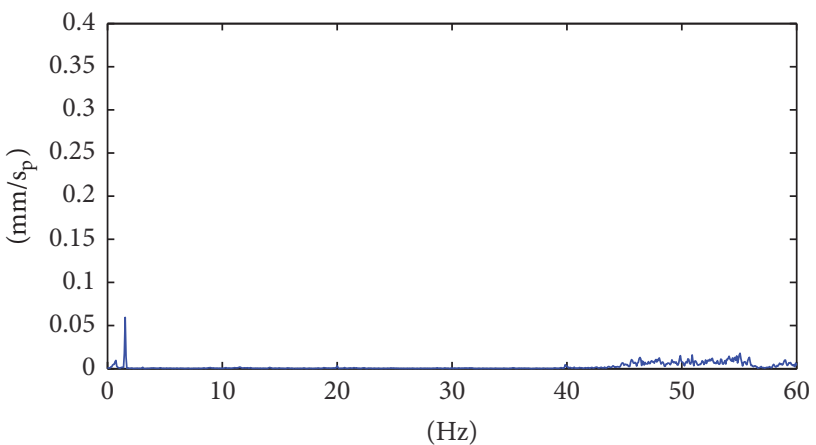

FIGURE 16: Measured shaft relative and bearing absolute vibrations at $X$ direction of the lower journal bearing, when generator rotor had an unbalance G4.25. 
TABLe 7: Natural frequencies of 1st Backward Precession Mode (BPM), 2nd Forward Precession Mode (FPM), 3rd BPM, and 4th FPM, with generator excited and unexcited.

\begin{tabular}{|c|c|c|c|c|c|c|c|c|}
\hline \multirow{3}{*}{ Bearing clearance condition } & \multicolumn{8}{|c|}{ Natural frequencies [Hz] } \\
\hline & \multicolumn{4}{|c|}{ Generator excited } & \multicolumn{4}{|c|}{ Generator unexcited } \\
\hline & 1st BPM & 2nd FPM & 3rd BPM & 4th FPM & 1st BPM & 2nd FPM & 3rd BPM & 4th FPM \\
\hline A & 4.71 & 5.12 & 7.18 & 7.91 & 5.24 & 5.74 & 7.28 & 7.93 \\
\hline $\mathrm{A}^{*}$ & 4.84 & 5.30 & 7.23 & 7.93 & 5.35 & 5.89 & 7.33 & 7.95 \\
\hline B & 4.19 & 4.70 & 7.08 & 7.86 & 4.84 & 5.36 & 7.16 & 7.87 \\
\hline $\mathrm{C}$ & 3.11 & 3.77 & 6.95 & 7.79 & 4.01 & 4.59 & 7.02 & 7.80 \\
\hline $\mathrm{D}$ & 3.11 & 4.19 & 6.99 & 7.80 & 4.02 & 4.91 & 7.05 & 7.81 \\
\hline
\end{tabular}

The symbol "* "indicates that the shaft position is different. In the clearance condition A the pad clearances are in the nominal values ( $200 \mu \mathrm{m})$ and the shaft is centered at coordinates $(0,0)$. In clearance condition $A^{\star}$ the pad clearances are once more in the nominal values but the shaft has an eccentricity of $67 \mu \mathrm{m}$.

TABLE 8: Comparison of measured and simulated vibrations in $X$ direction, in an LHG operating at speed-no-load, with an unbalance grade ISO G4.25 in the generator rotor, at the rotating frequency.

\begin{tabular}{|c|c|c|c|c|c|c|}
\hline \multirow{2}{*}{ Journal bearing } & \multicolumn{3}{|c|}{ Shaft relative vibrations $\left[\mu \mathrm{m}_{\mathrm{p}}\right]$} & \multicolumn{3}{|c|}{ Bearing absolute vibrations $\left[\mathrm{mm} / \mathrm{s}_{\mathrm{p}}\right]$} \\
\hline & Measured & Simulated & Error & Measured & Simulated & Error $[\%]$ \\
\hline Upper & 40.5 & 41.0 & $1.2 \%$ & 0.218 & 0.261 & $19.7 \%$ \\
\hline Lower & 38.3 & 38.6 & $0.8 \%$ & 0.059 & 0.107 & $81.4 \%$ \\
\hline
\end{tabular}

The lower diagrams show Welch's power spectral density estimate of these signals, obtained using a Hann window with 8192 points. Shaft vibration spectra were calibrated for displacement in $\mu \mathrm{m}$, while bearing vibrations spectra were calibrated for velocity in $\mathrm{mm} / \mathrm{s}$, both in peak values.

The Rigid Body Model was used to simulate the hydrogenerator dynamic behavior with the same unbalance level in the generator rotor and with the nominal parameters shown in Table 2. The shaft and bearing vibration signals, obtained in this simulation, were significantly different from those measured and shown in the last two figures. Considering the reductions in the bearing stiffness described in Section 4.1, these parameters were diminished until simulated and measured shaft vibrations had similar values. Only the stiffness of the generator journal bearings was reduced, and the remaining parameters of the model were kept constant. The upper journal bearing stiffness values $\left(k_{1 x x}\right.$ and $\left.k_{1 y y}\right)$ were reduced from 6.67 to $0.77 \mathrm{GN} / \mathrm{m}$, whereas the lower journal bearing stiffness values $\left(k_{3 x x}\right.$ and $k_{3 y y}$ ) were diminished from 2.86 to $0.63 \mathrm{GN} / \mathrm{m}$. The upper journal bearing stiffness $(0.77 \mathrm{GN} / \mathrm{m})$ is between the stiffness shown in Table 5 with clearance condition $\mathrm{C}$ and the values experimentally estimated in [36]; therefore, this is a feasible value.

Figures 17 and 18 show the vibration signals obtained in the described simulations. Table 8 compares the measured and simulated vibrations at the rotating speed, in peak values. This table shows that errors are negligible for shaft vibrations but they are considerable for bearing vibrations. For shaft vibrations, besides the intrinsic errors of transducers accuracy class, the errors originated by the mechanical and the electrical runout should be considered. For bearing vibrations, despite the high sensitivity $(1000 \mathrm{mV} / \mathrm{g})$ and low cutoff frequency $(0.5 \mathrm{~Hz})$ of the accelerometers, it should be noted that the acceleration signals at the rotating speed $(92.3 \mathrm{r} / \mathrm{min})$ have only a fraction of millivolts. For instance, the vibration measured in the upper journal bearing $(0.218 \mathrm{~mm} / \mathrm{s}$ in Table 8$)$ generates only a $0.21 \mathrm{mV}$ signal. This low amplitude makes the signal handling difficult, especially in such noisy environment. This could partially justify the significant errors observed in bearing absolute vibrations. Therefore, the piezoelectric accelerometers must be replaced by a more suitable absolute vibration transducer, with better performance in the low-frequency range.

These simulations indicate that the simplified 10-DOF Rigid Body Model may describe adequately the dynamic behavior of an LHG in the frequency domain. This simulation also confirms that bearing stiffness is much lower than the theoretical values determined using the nominal clearances, as was verified in Section 4.1.

\section{Concluding Remarks}

The typical changes in the operating and boundary conditions of LHG journal bearings make the accurate determination of bearing dynamic coefficients and, consequently, the prediction of the dynamic behavior and the vibration monitoring of these machines difficult. This article has proposed a back-tobasics step, the application of simplified mathematical models to assist fault detection and fault diagnosis in LHG, and it has illustrated this proposal by modeling $700 \mathrm{MW}$ hydrogenerators. Though simplified, these models were validated by comparing their results with the results obtained using more refined models or with real vibration signals, measured in the modeled hydrogenerators. Among other results, these models have shown that the journal bearing stiffness of LHG may be one order of magnitude lower than the theoretical values, due to dimensional changes in the bearing housing, which are usually neglected even by the most sophisticated bearing models. 


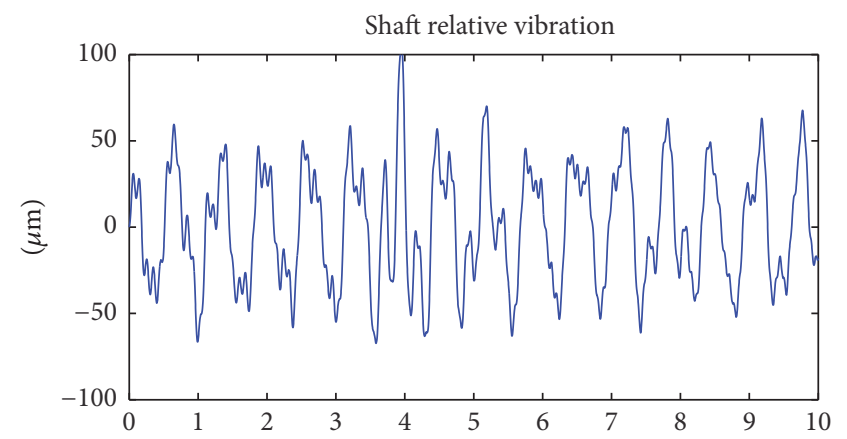

(s)

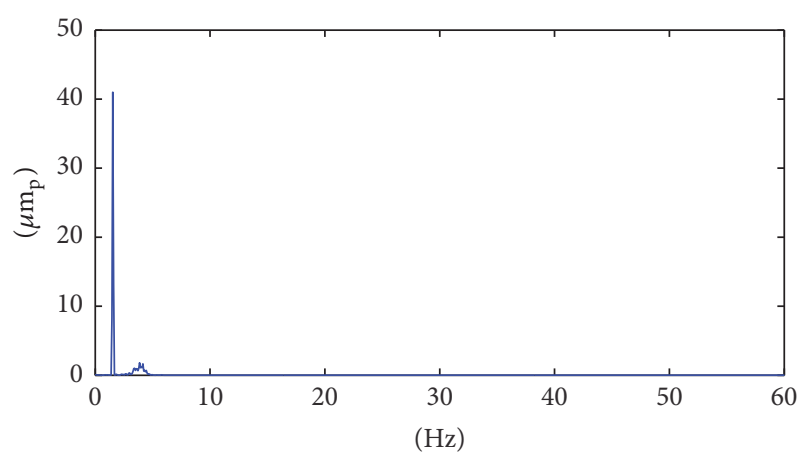

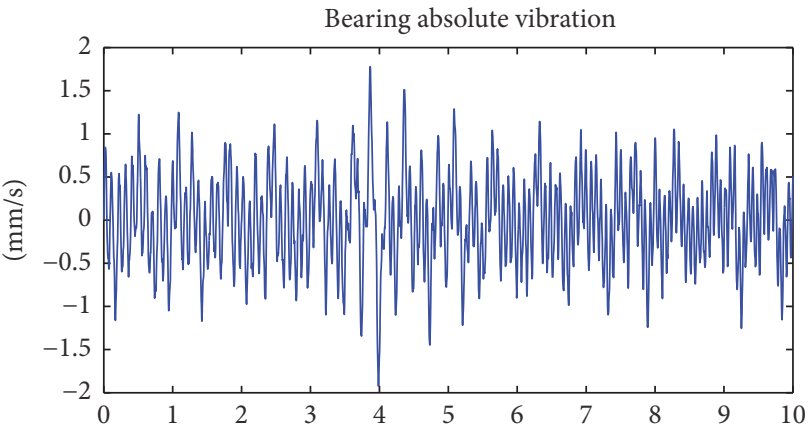

(s)

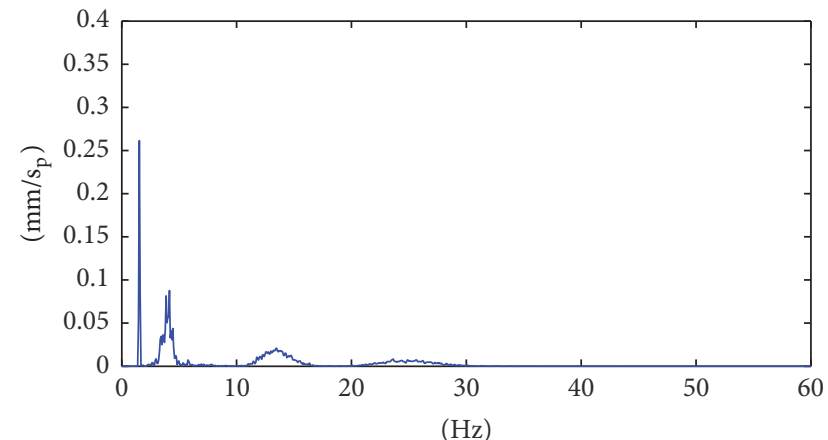

FIGURE 17: Simulated shaft relative and bearing absolute vibrations at $X$ direction of the upper journal bearing, when generator rotor had an unbalance G4.25.

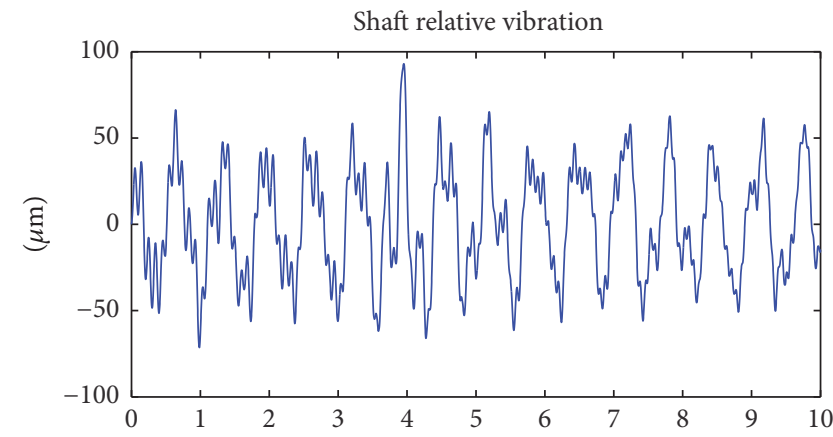

(s)

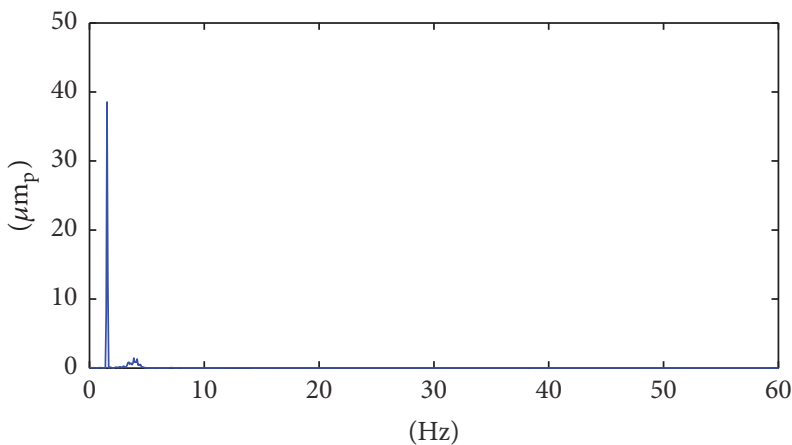

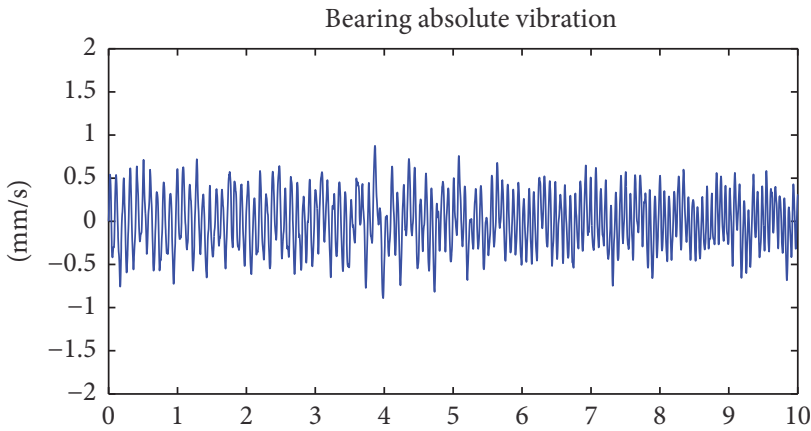

$(\mathrm{s})$

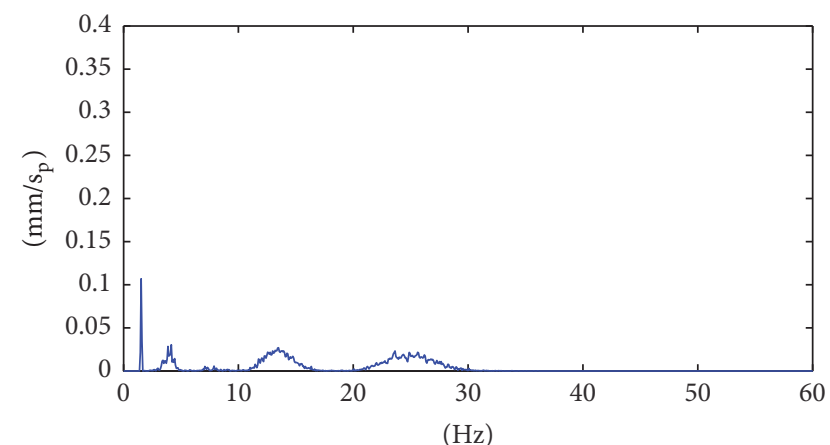

FIGURE 18: Simulated shaft relative and bearing absolute vibrations at $X$ direction of the lower journal bearing, when generator rotor had an unbalance G4.25. 
The satisfactory performance of simplified models and their effectiveness in assisting fault detection and fault diagnosis in LHG naturally depend on the accurate definition of bearing operating and boundary conditions. Therefore, to minimize the probability of false positive and false negative alarms, the improvement of this accuracy is suggested. One may mention, as examples, the monitoring of all bearing pads temperatures, the using of four transducers to measure shaft relative vibrations at each journal bearing, and the search for better transducers to measure bearing absolute vibrations in the range of LHG rotating speed.

\section{Conflicts of Interest}

The authors declare that there are no conflicts of interest regarding the publication of this paper.

\section{Acknowledgments}

The authors are grateful to Itaipu Binacional, to the Itaipu Technological Park, and to the Center for Advanced Studies on the Safety of Dams for the encouragement in this research. R. D. Machado gratefully acknowledges the financial support provided by the Brazilian government agency CNPq (Conselho Nacional de Desenvolvimento Científico e Tecnológico) under the research Grants 312241/2015-1.

\section{References}

[1] F. A. Hamill, "Sayano Shushenskaya accident: presenting a possible direct cause," in International Water Power Dam Construction, pp. 30-36, 2010.

[2] W. Youlin, L. Shengcai, L. Shuhong, D. Hua-Shu, and Q. Zhongdong, Vibration of Hydraulic Machinery, Mechanisms and Machine Science Series, Springer, Dordrecht, The Netherlands, 2013.

[3] R. B. Randall, Vibration-Based Condition Monitoring: Industrial, Aerospace and Automotive Applications, John Wiley \& Sons, 2011.

[4] C. Farrar and K. Worden, "An introduction to structural health monitoring," Philosophical Transactions of the Royal Society of London A, vol. 365, no. 1851, pp. 303-315, 2007.

[5] L. A. Vladislavlev, Vibration of Hydro Units in Hydroelectric Power Plants, Amerind Publishing Company, New Delhi, India, 1979.

[6] T. Someya, Journal-Bearing Databook, Springer, Heidelberg, Germany, 1989.

[7] International Standard Organization, "Mechanical vibrationevaluation of machine vibration by measurements on rotating shafts," ISO 7919, ISO, Genebra, Switzerland, 2005.

[8] "Mechanical vibration-evaluation of machine vibration by measurements on non-rotating," ISO 10816, International Standard Organizatio, Genebra, Switzerland, 2000.

[9] G. C. Brito Jr., R. D. Machado, A. Chaves Neto, and M. F. Martini, "Experimental aspects in the vibration-based condition monitoring of large hydrogenerators," International Journal of Rotating Machinery, vol. 2017, Article ID 1805051, 14 pages, 2017.

[10] Itaipu, "Special measurements in unity 14 bearings," 1987.

[11] R. Cardinali, R. Nordmann, and A. Sperber, "Dynamic simulation of non-linear models of hydroelectric machinery," Mechanical Systems and Signal Processing, vol. 7, no. 1, pp. 29-44, 1993.
[12] R. K. Gustavsson and J.-O. Aidanpää, “The influence of nonlinear magnetic pull on hydropower generator rotors," Journal of Sound and Vibration, vol. 297, no. 3-5, pp. 551-562, 2006.

[13] X. Si, W. Lu, and F. Chu, "Lateral vibration of hydroelectric generating set with different supporting condition of thrust pad," Shock and Vibration, vol. 18, no. 1-2, pp. 317-331, 2011.

[14] Itaipu, Itaipu Hydroelectric Project: Engineering Characteristics, Tab Marketing Editorial, Porto Alegre, Brazil, 2009.

[15] M. Nässelqvist, R. K. Gustavsson, and J.-O. Aidanpää, "Resonance problems in vertical hydropower unit after turbine upgrade," in Proceedings of the 24th Symposium on Hydraulic Machinery and Systems, Foz do Iguaçu, Brazil, 2008.

[16] R. K. Gustavsson and J.-O. Aidanpää, "Using strain gauges to measure load on hydro generator guide bearings," Hydro Review Worldwide Magazine, pp. 1-5, 2003.

[17] M. Nässelqvist, R. K. Gustavsson, and J.-O. Aidanpää, "Bearing load measurement in a hydropower unit using strain gauges installed inside pivot pin," Experimental Mechanics, vol. 52, no. 4, pp. 361-369, 2012.

[18] M. Nässelqvist, R. K. Gustavsson, and J.-O. Aidanpää, "A methodology for protective vibration monitoring of hydropower units based on the mechanical properties," Journal of Dynamic Systems, Measurement and Control, vol. 135, no. 4, Article ID 041007, pp. 71-78, 2013.

[19] Y. Xu, Z. Li, and X. Lai, "Dynamic model for hydro-turbine generator units based on a database method for guide bearings," Shock and Vibration, vol. 20, pp. 411-421, 2013.

[20] R. Tiwari, A. W. Lees, and M. I. Friswell, "Identification of dynamic bearing parameters-a review," The Shock and Vibration Digest, vol. 36, no. 2, pp. 99-124, 2004.

[21] T. W. Dimond, P. N. Sheth, P. E. Allaire, and M. He, "Identification methods and test results for tilting pad and fixed geometry journal bearing dynamic coefficients-a review," Shock and Vibration, vol. 16, no. 1, pp. 13-43, 2009.

[22] A. Muszynska, Rotordynamics, Taylor \& Francis Group, Boca Raton, Fla, USA, 2005.

[23] Y. Wang, Y. Gao, Y. Cui, and Z. Liu, "Establishment of approximate analytical model of oil film force for finite length tilting pad journal bearings," International Journal of Rotating Machinery, vol. 2015, Article ID 531209, 11 pages, 2015.

[24] A. Sperber and H. I. Weber, "Dynamic models of hydroelectric machinery," Journal of the Brazilian Society of Mechanical Sciences, vol. 13, no. 1, pp. 29-59, 1991.

[25] I. Boldea, Synchronous Generators, CRC Taylor \& Francis, Boca Raton, Fla, USA, 2006.

[26] B. J. Hamrock, S. R. Schmid, and B. O. Jacobson, Fundamentals of Fluid Film Lubrication, Marcel Dekker, New York, NY, USA, 2nd edition, 2004.

[27] P. Sahoo, Engineering Tribology, PHI Learning Private, New Delhi, India, 2013.

[28] G. C. Brito Jr., H. I. Weber, and A. G. A. Fuerst, "Simplified calculation of dynamic coefficients for hydrodynamic bearings in large hydro generators," in Proceedings of the 6th International Conference on Vibrations in Rotating Machinery, Oxford, UK, September 1996.

[29] G. B. Daniel and K. L. Cavalca, "Evaluation of the thermal effects in tilting pad bearing," International Journal of Rotating Machinery, vol. 2013, Article ID 725268, 17 pages, 2013.

[30] R. Cardinali, Modeling and diagnostics applications in vertical rotating machines [Doctoral Thesis in Mechanical Engineering], Campinas State University, Campinas, Brazil, 1992.

[31] J. G. Fox and J. Mahanty, "The effective mass of an oscillating spring," American Journal of Physics, vol. 38, no. 1, pp. 98-100, 1970. 
[32] B. Balachandran and E. B. Magrab, Vibrations, Cengage Learning, Toronto, Canada, 2009.

[33] J.-C. Luneno, J.-O. Aidanpää, and R. Gustavsson, "Model based analysis of coupled vibrations due to the combi-bearing in vertical hydroturbogenerator rotors," Journal of Vibration and Acoustics, vol. 133, no. 6, Article ID 061012, 2011.

[34] G. Genta, Dynamic of Rotating Systems, Springer, 2005.

[35] G. C. Brito Jr., Dynamic behaviour of journal bearing of large hydro generators [M.Sc. Dissertation in Mechanical Engineering], Campinas State University, Campinas, Brazil, 1995.

[36] G. C. Brito Jr., R. D. Machado, V. Abreu Jr., and A. Chaves Neto, "Using autoregressive models for damage detection in guide bearings of hydro generating units," in Proceedings of the 34th CILAMCE-Ibero-Latin American Congress on Computational Methods in Engineering, Pirenópolis, Brazil, 2013. 


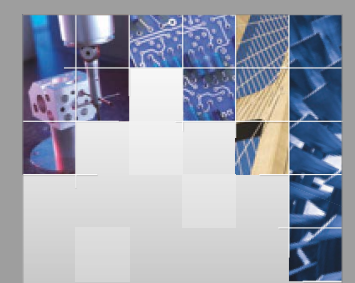

\section{Enfincering}
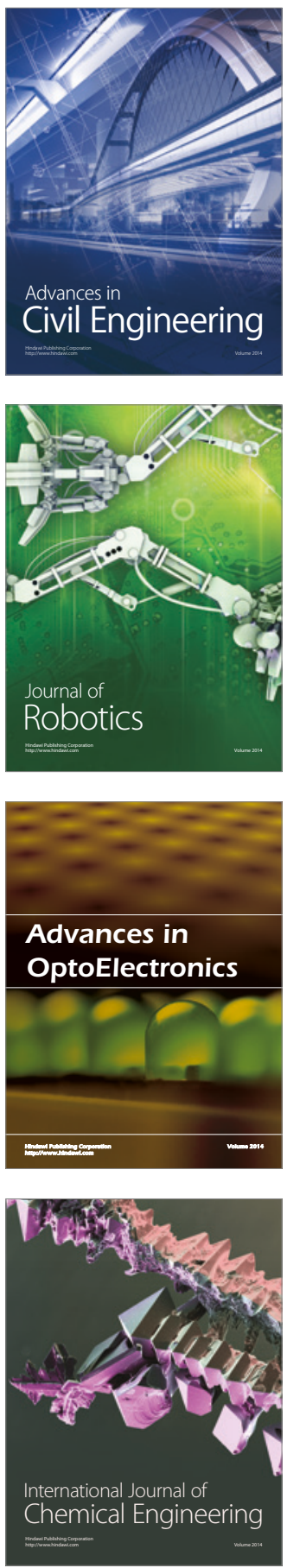

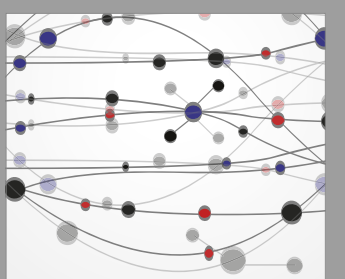

The Scientific World Journal

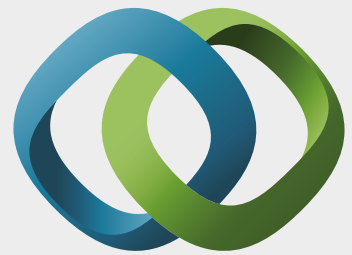

\section{Hindawi}

Submit your manuscripts at

https://www.hindawi.com
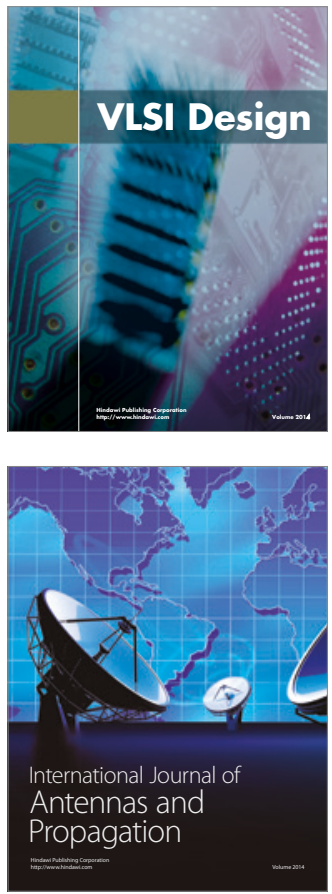

\section{Rotating}

Machinery
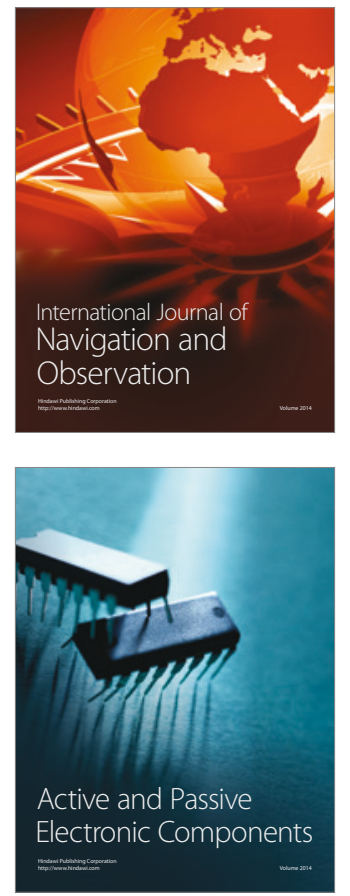
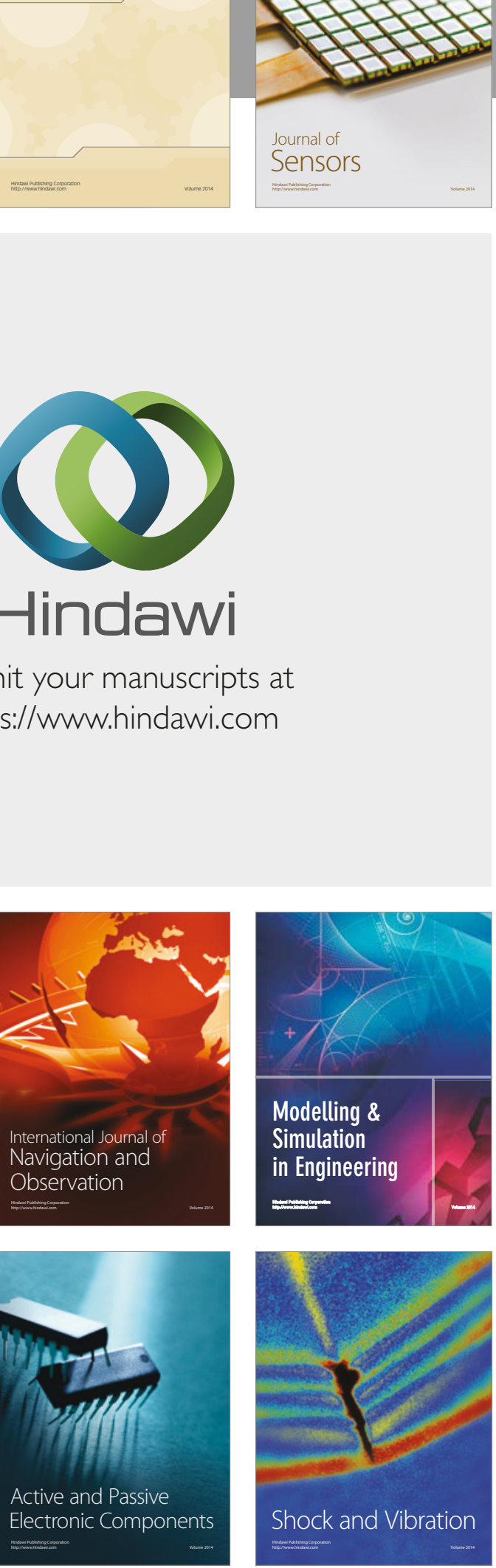
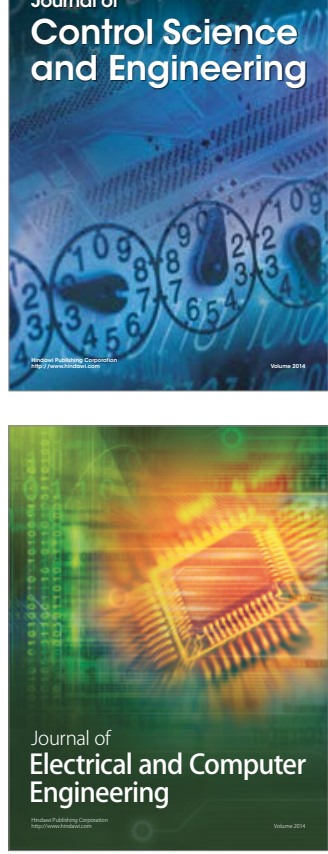

Distributed

Journal of

Control Science

and Engineering
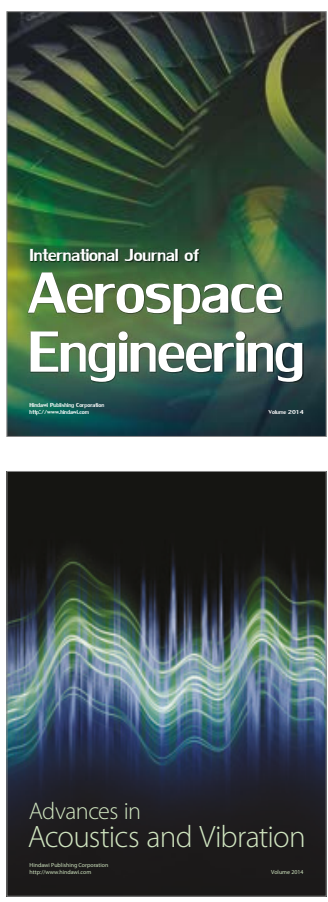

Sensor Networks 